\title{
Proxy control
}

\section{A new species of control in grammar}

\author{
Aaron Doliana $^{1} \cdot$ Sandhya Sundaresan $^{2}$
}

Received: 21 November 2017 / Accepted: 22 December 2020 / Published online: 21 January 2021

(C) The Author(s) 2021

\begin{abstract}
The control dependency in grammar is conventionally distinguished into two classes: exhaustive $(i \rightarrow i)$ and non-exhaustive $(i \rightarrow i+(j))$. Here, we show that, in languages like German and Italian, some speakers allow a new kind of "proxy control" which differs from both, such that, for a controller $i$, and a controllee $j, j=\operatorname{proxy}(i)$. The proxy function picks out a set of individuals that is discourse-pragmatically related to $i$. For such speakers, the German/Italian proxy control equivalent of the sentence: "Maria $i$ asked Bill $j$ (for permission) [PRO proxy $(i)$ to leave work early]" would thus mean that Maria asked Bill for permission for some salient set of individuals related to herself to leave early. We examine the theoretical and empirical properties of this new control relation in detail, showing that it is irreducible to other, more familiar referential dependencies. Using standard empirical diagnostics, we then illustrate that proxy control can be instantiated both as a species of obligatory control (OC) and non-obligatory control (NOC) in German and Italian and develop a syntactic and semantic model that derives each and details the factors conditioning the choice between the two. We also investigate the factors that condition different degrees of exhaustiveness (exhaustive vs. partial vs. proxy) in control, which then sheds light on why proxy control obtains in some languages, but not others and, within a language, is possible for some speakers but not others.
\end{abstract}

Authors are listed alphabetically and have the status of joint first authors. A. Doliana is bilingual in German and Italian. S. Sundaresan is a native speaker of English.

\footnotetext{
$\bowtie$ A. Doliana

doliana@umd.edu

S. Sundaresan

sandhya@sndrsn.org

1 Department of Linguistics, University of Maryland, 1401 Marie Mount Hall, College Park, MD 20742, USA

2 Seminar for English Philology, Georg-August-Universität Göttingen, Käte-Hamburger-Weg 3, 37073 Göttingen, Germany
} 
Keywords (Non-)obligatory control · PRO vs. pro · Proxy · Exhaustive vs. non-exhaustive control $\cdot$ Phi features $\cdot$ Agree $\cdot$ Modal quantification · Semantic extension - Syntax-Semantics interface · Italian · German · Parametric variation . Speaker variation

\section{Overview}

Control in grammar is traditionally distinguished as obligatory (OC) vs. nonobligatory (NOC), with the former being more syntactically and semantically restricted than the latter (Williams 1980; Hornstein 1999; Landau 2013; McFadden and Sundaresan 2016, 2018; Fischer 2018). A different kind of classification has to do with degrees of exhaustification under control (see Stiebels 2007). In cases of exhaustive control, the reference of the controller is identical to that of the controllee $(i \rightarrow i)$ : e.g. "Marie ${ }_{i}$ tried $\left[\mathrm{EC}_{i}\right.$ to sleep]". In cases of non-exhaustive partial or split control, the reference of the controller is properly contained in that of the controllee $(i \rightarrow i+(j))$ : e.g. "Marie $i$ wanted $\left[\mathrm{EC}_{i+}\right.$ to meet]". In this paper, we show that certain languages seem to allow an additional type of control, which we term "proxy control" in analogy with instances of proxy anaphora (Jackendoff 1992; Schladt 2000; Reuland and Winter 2009), and is defined in (1):

\section{Generalized proxy control (OC and NOC) relation:}

a. For any two sets of individuals $i$ and $j$, where $i$ is a core participant in a permission-seeking or -granting speech-event $e_{1}$ and $j$ is a core participant in $e_{2}$, an eventuality that is consistent with permission being granted in $e_{1}, j=\operatorname{proxy}(i)$ iff:

(i) in $e_{1}, i$ acts on behalf of $j$;

(ii) in $e_{2}, j$ stands in for $i$;

(iii) $i$ and $j$ are directly associated through some discourse-salient group or activity.

b. In cases of proxy control, if a controller denotes $i$ and the controllee denotes $j, j=\operatorname{proxy}(i)$.

We illustrate this with the gerundival example from English in (2):

(2) Scenario: Maria is asking Susan, her boss, for her teammates to leave work early. Maria herself must stay late and complete an overdue project.

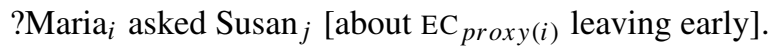

In (2), Maria acts as her teammates' spokesperson in asking for permission for them to leave early. Conversely, the controllee $j$ serves as a proxy of $i$ in the embedded eventuality for which permission is being sought: the teammates in (2) serve as Maria's proxy in that they are the ones who would be leaving early, not Maria herself. The proxy control relation thus involves a mapping of $i \rightarrow \operatorname{proxy}(i)$ between the controller and controllee. This is a new kind of relation: it is neither the strict 
identity relation of exhaustive control, nor the subset-superset relation of classic nonexhaustive control. In English, the availability of proxy control is quite restricted. For some speakers, it is simply unavailable; for others, it is available exclusively as a species of NOC in gerundival clauses like in (2). But in other languages, like the varieties of German and Italian we will primarily be focusing on here, proxy control is more readily available across speakers, obtains in a wider range of grammatical environments, and is available as a species of OC and NOC. The fundamental goal of this paper is to motivate and examine this new type of control thoroughly from the ground up, and to develop a theory of this phenomenon which explains not only its core properties but also captures the formal input conditions that determine when it can obtain and when it cannot.

Our discussion throughout will be closely guided by the native speaker intuitions of one of the authors (who is bilingual in Italian and German) and primary data collected via face-to-face elicitations and online questionnaires from 46 (37 German and 9 Italian) other native speakers. We first show that proxy control constitutes a primitive grammatical dependency in its own right and cannot be reduced to other more familiar referential dependencies, like partial control, metonymic control, arbitrary control, and control shift. Using standard empirical diagnostics, we show that, while proxy control is only possible as a species of NOC for a substantial number of our consultants, for a smaller subset of speakers, it is also available as a species of OC. Based on careful empirical testing, we show that: (i) proxy OC is not a special case of proxy NOC; (ii) proxy OC and proxy NOC involve distinct underlying structures in syntax and undergo separate life-cycles.

For us, proxy control (OC and NOC) involves a nested or cyclic control, involving two levels of clausal embedding corresponding to two nested layers of modal quantification. The fundamental difference between proxy OC and proxy NOC is that the former alone involves a syntactic dependency between the controller and controllees (see Boeckx et al. 2010; Landau 2015b; McFadden and Sundaresan 2018, a.o.) in the medial and innermost clauses. This dependency is mediated by the complementizers heading these $\mathrm{CP}$ phases: a $C_{\text {permission }}$ head which introduces a semantics of permission in the innermost $\mathrm{CP}$ and an illocutionary $\mathrm{C}_{ \pm w h}$ head in the medial one. We present empirical evidence to show that the syntactic dependency between the controller and controllees can only yield an $i \rightarrow i$ relation; the proxy reference of the controllee must thus be established post-syntactically, via semantic extension (building on insights in Pearson 2016, for partial control). In cases of proxy NOC, the innermost controllee never enters into a syntactic relation with the controller but, rather, Agrees with a logophoric operator within its own clause (again mediated by $C_{\text {permission }}$ ). This logophoric operator (denoting $\operatorname{proxy}(i)$ ) discourse-pragmatically refers to the controller (denoting $i$ ), yielding a superficial $i \rightarrow \operatorname{proxy}(i)$ control relation. We show that this allows the controllee, in such cases, to bear syntactic features corresponding to $\operatorname{proxy}(i)$ (for a controller bearing features corresponding to $i$ ): thus, no semantic extension is needed here. The life-cycles for proxy OC and proxy NOC are illustrated below: ${ }^{1}$

\footnotetext{
${ }^{1}$ We remain agnostic for now whether the medial controllee in cases of proxy NOC enters into an oC or NOC relation with the controller.
} 


\section{Proxy OC: syntactic life-cycle:}

a. [Marie $i$ asked [ $C_{[+w h]} \mathrm{PRO}_{i}$ to [ $C_{\text {permission }} \mathrm{PRO}_{i}$ leave early] ].

b. $\quad\left[\mathrm{DP} V\left[\mathrm{C}_{[+w h]}\right.\right.$ PRO ... $\left[\mathrm{C}_{\text {permission }}\right.$ PRO ...] ] ]

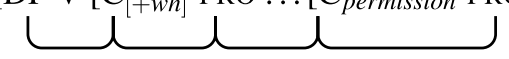

c. Semantic extension: $i \rightarrow \operatorname{proxy}(i)$

Final Output: Marie $i$ asked [ $C_{+w h} \mathrm{PRO}_{i}$ [ $C_{\text {permission }} \mathrm{PRO}_{\text {proxy }(i)}$ to leave early]]

(4) Proxy NOC: life-cycle:

Controller ${ }_{i} \ldots\left[\mathrm{C}_{+w h} \mathrm{PRO}_{i} \ldots\left[\log P \mathrm{OP}_{\text {proxy }(i)} \ldots\left[\mathrm{C}_{[\text {permission }]}^{\left.\left.\mathrm{C}_{1} \ldots\left[\mathrm{EC}_{\text {proxy }(i)} \ldots\right]\right]\right]}\right]\right.\right.$

The final section details the factors conditioning variation for proxy control at the speaker, dialectal and crosslinguistic levels. For speakers that allow proxy control in theory, we address the grammatical factors that determine whether this is judged to be a species of OC or NOC. For speakers that do not allow proxy control under a given predicate, both within German and Italian, and in other languages like English, we discuss the grammatical loci that condition the choice.

\section{Introducing proxy control}

In this section, we introduce proxy control with primary examples from German and Italian, obtained via a combination of online surveys and face-to-face elicitations and further corroborated by the native speaker intuitions of one of us, who is bilingual in both languages. Consider first the sentence in (5a) from Italian. It gets different control readings depending on which discourse scenario it is evaluated against:

a. La maestra $i$ ha chiesto al contadino $_{j}\left[\mathrm{di} \mathrm{EC}_{i, i+k, p r o x y(i)}\right.$ poter the teacher has asked to.the farmer $\mathrm{C}$ may.INF accarezzare l' asino]. pet.INF the donkey

'The teacher $i$ asked the farmer [for permission $\mathrm{EC}_{i, i+k, p r o x y(i)}$ to pet the donkey].'

b. Exhaustive Scenario: There is a donkey next to the elementary school. The teacher would like to pet it and asks the farmer if she is allowed to do that.

c. Partial Scenario: There is a donkey next to the elementary school. The teacher and her students would like to pet it. The teacher asks the farmer if she and the kids can do that.

d. Proxy Scenario: There is a donkey next to the elementary school. The kids would like to pet it. The teacher asks the farmer if they are allowed to do that.

Under the Exhaustive Scenario in (5b), the teacher (controller) asks the farmer whether she herself (controllee) may pet the donkey $(i \rightarrow i)$. In the Partial Scenario 
in $(5 \mathrm{c})$, the teacher (controller) is asking whether she and her students (controllee) may pet the donkey $(i \rightarrow i+)$.

The Proxy Scenario in (5d) is different from both. Here, the teacher (controller) asks the farmer whether her students (controllee) may pet the donkey. The discoursecontext makes clear that she herself will not be petting the donkey. Thus, the teacher is a spokesperson for a group of individuals that excludes herself; the students themselves serve as a proxy for the teacher in the intended petting event. This new control relation is neither $i \rightarrow i$ nor $i \rightarrow i+$ : rather, it is an $i \rightarrow \operatorname{proxy}(i)$ dependency which maps the teacher to a set of students that is discourse-contextually related to her and happens to exclude her.

(6b) now illustrates proxy control in German for the object control reading of the verb versprechen ('promise'); note that proxy control would also be possible under a subject-control reading of bitten ('ask'). Here, we illustrate only the proxy scenario: but it should be noted that partial and exhaustive readings are equally available under the appropriate discourse-contexts, just as in Italian.

a. Proxy Scenario: The inmates of a prison inform the warden that they want to spend their breaks outside in good weather. The kind prison-director promises the warden that they should be able to do this.

b. Der Gefängnisdirektor $i$ hat dem Wärter $j$ versprochen, $\left[\mathrm{EC}_{\text {proxy }}(j)\right.$ bei the prison.director has the warden promised with schönem Wetter die Pause draußen verbringen zu dürfen]. nice weather the break outside spend.INF to may.INF

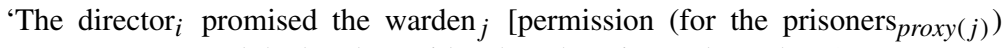
$\mathrm{EC}_{\text {proxy }(j)}$ to spend the break outside when there is good weather].'

Descriptively, this involves the same kind of control relation as in Italian (5d). In (6b), the director promises the warden that the prisoners, rather than the warden himself (which indeed would be pragmatically odd given that he is not imprisoned), to spend their break outside. The warden is thus promised permission on behalf of the prisoners in the matrix illocutionary event; the prisoners, in turn, are the warden's proxy in the intended spending-the-break-outside event. The control relation is thus again of the form $i \rightarrow \operatorname{proxy}(i)$, with the discourse-context making clear that $i$ is not included in $\operatorname{proxy}(i)^{2}$

\footnotetext{
${ }^{2}$ The proxy controllee can also denote an atomic individual, given the right context., e.g. in the Italian example in (2).
}

i. $\quad$ a. Proxy Scenario: The speaker turned in her homework after the official deadline. A classmate asks her if it was a problem. She replies that it was no problem because her brother Julian, who is at the same school a couple years above, had asked the teacher for permission to do so.

b. $\quad \ldots$ perché $\operatorname{Julian}_{i}$ aveva pregato la $\operatorname{prof}_{j} \quad\left[\mathrm{di} \mathrm{EC}_{\text {proxy(i) }}\right.$ poter-li consegnare il $\ldots$ because Julian had asked the teacher C may.INF-3PL hand.in.INF the giorno dopo].

day after

$\because .$. because $\operatorname{Julian}_{i}$ had asked the teacher $j$ [for permission (for me proxy $(i)$ ) $\mathrm{EC}_{\text {proxy }(i)}$ to hand them in the next day].' 
We can thus generalize the conditions of proxy control, described above, as in (7):

In cases of proxy control, a set of individuals $X$ asks permission from another set of individuals $Y$, or $Y$ offers to grant $X$ permission, for a third set of individuals $Z$ to participate in some eventuality $E$. In the speech-event (of asking or promising permission), $X$ stands in for $Z$. In the sub-event for which permission is being promised or asked, $Z$ stands in for, or is a proxy of, $X .^{3}$

The suitability of $X$ to serve as a representative of $Z$, as well as the suitability of $Z$ to serve as a proxy of $X$ are conditioned by discourse-pragmatic factors. In the cases we have considered, $X$ and $Z$ must have some independent association, e.g. due to their joint participation in some socio-cultural activity, joint membership in a profession or via some familial or other personal relationship. The precise nature of this relationship is specified by the salient discourse and may well vary from one speaker to another.

\subsection{The requirement of illocutionary and permission modality}

A central property of proxy control sentences is that they must involve illocutionary predicates with a modality of deontic possibility or permission. This essentially means that proxy control, at least in the languages we have tested, obtains with permission-seeking and -granting predicates. In German and Italian, our primary object languages, this occurs to varying degrees with embedding verbs like Italian chiedere 'ask', pregare 'ask', permettere 'permit', ${ }^{4}$ promettere 'promise', assicurare 'assure', richiedere 'ask, demand' or German bitten 'ask', erlauben 'permit' (also understood illocutionarily), versprechen 'promise', and, more marginally, versichern 'assure'.

Often, the semantics of permission is further enforced by the presence of an overt modal in the embedded controlled clause, e.g. German dürfen (cf. Ex. (6) for German) or Italian poter (both roughly meaning 'may'). Our Italian and German consultants varied with respect to how important the addition of this overt modal was for the availability of proxy control. For the German/Italian author, the modal must be present in the control complement for partial or proxy control readings to obtain in Italian, but in German, this requirement is less strong. The conditions on the overtness of the modal in the controlled constituent thus clearly warrant further research. What is generally invariant is that, in all proxy control structures, there is a semantic interpretation of permission-seeking or -granting determined by an illocutionary act in the matrix clause. This requirement will factor prominently in our analysis of proxy control later in the paper.

\footnotetext{
${ }^{3}$ Strictly speaking, the proxy relationship is thus symmetric: the controller $X$ is a proxy for the controllee $Z$ in the matrix eventuality, just as $Z$ is a proxy for $X$ in the embedded eventuality. For the sake of clarity going forward, we will retain the term "proxy" for the controllee alone: i.e. in cases of proxy control, the controllee $Z$ is the proxy of the controller $X$.

${ }^{4}$ This is also understood illocutionarily, in terms of (someone) granting permission, and not in the more bare sense of circumstances making something possible, as in a sentence like: "The beautiful weather permitted us to take a nice walk."
} 


\subsection{Proxy control is a grammatical primitive}

In this section, we show that proxy control is a primitive grammatical phenomenon and thus not straightforwardly reducible to other, more familiar, types of referential (i.e. control or other) dependency.

\subsubsection{Proxy control vs. control shift}

In cases of control shift, a predicate that typically effects subject control is "shifted" to yield object control; alternatively, a typically object control predicate shifts to yield subject control. For instance, promise typically effects subject control, as in (8a), but with the (overt or covert) addition of permission modality in the control complement, the control relation is shifted to yield object control, as in (8b).
a. UNSHIFTED SUBJECT CONTROL:
$\mathrm{Grandpa}_{i}$ promised the children $_{j}$ [EC $i$ to stay up for the Late Show].
b. SHIFTED OBJECT CONTROL:
Grandpa $_{i}$ promised the children $_{j}$ [EC $_{j}$ to be able to stay up for the Late Show].

The converse holds for an object control predicate like ask where typical object control is shifted to subject control in the concomitant presence of a permission modal. It is reasonable to ask whether proxy control is parasitic on, and thus reducible to, control shift (or vice versa). Not only is control shift also affected by permission, but the examples of proxy control we have seen so far have all also involved control shift. In Italian (5a), we get proxy control under a subject control reading of chiedere ('ask') and in German (6b), proxy control is effected under an object control reading of versprechen ('promise').

But these similarities notwithstanding, control shift is neither a necessary nor sufficient condition for the availability of proxy control. Proxy control may obtain even in the absence of control shift. Permettere 'permit' in Italian (9b) is an object control predicate which is not shifted and nevertheless allows proxy control (note again that this predicate is used illocutionarily in the sense of the farmer granting permission):

a. Proxy Scenario: There is a donkey next to the elementary school. The kids would like to pet it. The teacher asks the farmer if they are allowed to do that.

b. Il contadino $_{j}$ ha permesso alla maestra $i\left[\operatorname{di~EC}_{i, i+k, p r o x y}(i)\right.$ the farmer has allowed to.the teacher $\mathrm{C}$ poter $=$ lo accarezzare ]. may. INF $=$ it pet.INF

'The farmer permitted the teacher [EC $\mathrm{Eroxy}_{(i)}$ to pet it (the donkey)].'

Thus control shift is not necessary for proxy control to obtain. Conversely, control shift may obtain where proxy control cannot. Italian pregare 'ask' is typically an object control predicate. When it is shifted to subject control via passivization of the control clause, rather than through the addition of a permission modal, proxy control is not viable: 

$\mathrm{L}^{\prime}$ impiegat-a $_{i}$ ha pregato il suo collega ${ }_{j}$
the employee-F.SG has asked the his colleague.M.SG C
[di $\mathrm{EC}_{i, * \operatorname{proxy}(i)}$
essere trattat-a con più rispetto].
be.INF treated-F.SG with more respect

'The employee asked her colleague to be treated with more respect.'

(10) shows that control shift is also not a sufficient condition on proxy control.

We believe that the frequent co-occurrence of proxy control with control shift stems from the dependency of both proxy control and certain varieties of control shift on the presence of permission modality. A well-known property of (non-shifted) control is that the controller must correspond to the agent of the event described by the controlled complement (Lasnik and Fiengo 1974; Farkas 1988). This explains why an object control sentence like (11) with a non-agentive controlled subject sounds grammatically marked:

(11) ?? Marie $_{i}$ asked $\operatorname{Susan}_{j}$ [EC ${ }_{j}$ to get hungry/resemble her brother].

Uegaki (2011) convincingly argues that control shift obtains under special circumstances where this agentivity requirement is not satisfied. This immediately explains why control shift obtains both when the controlled complement is passivized and when it involves permission modality (e.g. "Mary $i$ asked Susan [EC $_{i}$ to be allowed...]"). In both these cases, the controlled subject does not correspond to the agent of the event described by the complement. Assuming that this is correct, the input conditions for control shift (Sag and Pollard 1991; Petter 1998, for discussion of control shift) are ultimately distinct from those for proxy control: the former is dependent on the thematic properties of the controlled subject (which can crucially be manipulated in the scope of permission modality) while the latter is dependent on permission modality directly. Thus, although the input conditions for control shift and proxy control overlap in many cases, the two ultimately delineate distinct grammatical phenomena.

\subsubsection{Proxy control vs. metonymic extension}

Another candidate for comparison is metonymic extension, illustrated in sentences like (12) (going back to observations in Nunberg 1979):

(One nurse to another) The head wounds in Room 426 needs/*need a fresh IV.

In (12), the agreement on the root verb does not match the plural marking on head wounds, but is singular. The reason, it is surmised, is that such agreement is triggered, not by head wounds but by its metonymic referent, denoting the (atomic) patient in Room 426 who sports these head wounds. Metonymic extension is also attested in German and Italian, as illustrated for Italian (13):

\footnotetext{
Ti/Lo hanno chiuso dentro. you/him have.3PL closed in

Literal: 'They closed you/him in.'

Intended: 'They parked in your/his car' (You/he need not to be in it).
} 
Landau (2013), citing Postal (2004), has illustrated that metonymic extension can also apply to control constructions, as in (14). ${ }^{5}$ Again, analogous examples can be constructed for German (15) and Italian:

(14) $\mathrm{Sue}_{i}$ claims [EC $\mathrm{EC}_{\text {met }(i)}$ to be parked on Broad Street].

(15) $\mathrm{Sue}_{i}$ hat versucht [EC $\mathrm{Eet}_{\text {(i) }}$ nicht (total) zugeparkt zu werden].

Sue has tried not totally parked.in to PASS.INF

'Sue ${ }_{i}$ tried [EC met $(i)$ not to be totally parked.in].'

In both (14) and (15), the controller Sue is coreferent with an extension of herself, presumably her car or other vehicle of transport. If the individuals defined in the proxy control relation may involve animate as well as inanimate entities, then it seems plausible that Sue and Sue's car are also linked by a proxy relation.

But while it is undeniable that both phenomena involve, at their core, an extension of one of the referents in the sentence, they ultimately differ in at least two respects. For one, metonymic extension does not even require the presence of control, as the examples in (12)-(13) attest. In contrast, even in languages that do allow proxy control, like German and Italian, sentences like (16) are infelicitous under the given meaning, even with the presence of a permission modal: ${ }^{6}$
Die Lehrerin darf den Esel streicheln.
the teacher may the donkey pet
$\checkmark$ 'The teacher may pet the donkey.'
$\boldsymbol{X}$ 'The teacher's students may pet the donkey.'

For another, metonymic extension can obtain in the absence of permission modality, something that is impossible for proxy control, as we have seen.

An empirical reflex of these distinctions is that metonymic extension is crosslinguistically far less restricted than proxy control. The small sampling of proxy control vs. metonymic examples discussed so far already supports this view: while there is no English proxy control equivalent to Italian (5a) and German (6b), English (14) is clearly acceptable with a metonymic reading (but not with a proxy control reading). Once we add in a permission modal reading to the sentence in (14), a proxy + metonymic control reading becomes available in the Italian and German variants of this sentence (though again, not for English). In the purely metonymic reading in German (17a), Sue $(i)$ asks for permission for her car (met $(i))$ to be parked in a roofed parking space. The German example in (17b) involves metonymic extension on top of proxy extension: Sue $(i)$ is asking for permission on behalf of her friends $(\operatorname{proxy}(i))$ for them to park their car $(\operatorname{met}(\operatorname{proxy}(i)))$ on a roofed parking space. $^{7}$

\footnotetext{
${ }^{5}$ Postal's claim was not about control but about restrictions on metonymic shift with pronominal antecedence in finite clauses. Thanks to Idan Landau (p.c.) for alerting us to this data.

${ }^{6}$ Thanks to an anonymous reviewer for pointing out a variant of this example to us.

${ }^{7}$ We thank an anonymous reviewer for this improved version of the sentence.
} 
(17) $\mathrm{Sue}_{i}$ hat den Parkservice gebeten, [ausnahmsweise mal

Sue has the parking.service asked as.exception once

$\mathrm{EC}_{\{\operatorname{met}(i), \operatorname{met}(\operatorname{proxy}(i))\}}$ auf einem überdachten Stellplatz stehen zu dürfen]. on a roofed car.space stand to may

'Sue has asked the parking service [EC to be allowed to park on a roofed parking space this one time].'

a. Metonymic-Extension: $i \rightarrow$ met $(i)$ yielding Sue $\rightarrow$ Sue's car

b. METONYMIC + PROXY-EXTENSION:

$i \rightarrow \operatorname{proxy}(i):$ Sue $\rightarrow$ Sue's friends, AND

$\operatorname{proxy}(i) \rightarrow \operatorname{met}(\operatorname{proxy}(i)):$ Sue's friends $\rightarrow$ Sue's friend's car

Such clearly discernible differences show that the extension involved in metonymic extension and the one involved in proxy control obtain under distinct grammatical conditions. ${ }^{8}$

\subsubsection{Proxy control vs. pragmatically strengthened $P R O_{\text {arb }}$}

Bhatt and Izvorski (1998) propose that deontic modals involve an implicit generic external argument which can, under certain conditions, control the kind of arbitrary or impersonal reading associated with arbitrary PRO ("PRO arb"). An anonymous reviewer proposes that such an external argument might then also be interpreted as a proxy controller, given further referential restrictions due to pragmatic strengthening. This would be tantamount to stating that any additional readings (e.g. of permission modality) associated with proxy control arise purely due to pragmatic restrictions placed on this arbitrary control reading. Here, we show that such an analysis cannot be extended to the cases of proxy control in German and Italian discussed here.

First, it can be shown that proxy control is possible even in configurations where $\mathrm{PRO}_{\text {arb }}$ is not. Bhatt and Izvorski show that arbitrary control obtains just in case the following conditions hold: (i) an implicit argument is present, and (ii) the sentence containing this implicit argument is generic. If proxy control is reducible to the presence of $\mathrm{PRO}_{a r b}$, then it should be impossible whenever one of these two conditions is blocked. One way to block genericity is to have a specific time reference, e.g. by placing the control structure in the scope of an episodic past. This yields minimal pairs like (18a) vs. (18b) (Bhatt and Izvorski 1998, 8; \#arb added): ${ }^{9}$

a. $\quad\left[\mathrm{PRO}_{a r b}\right.$ to write haiku] is fun.

b. Yesterday, [PRO\#arb to write haiku] on the grass was fun.

\footnotetext{
${ }^{8}$ Still, both ultimately involve a grammatical relation between two sets of individuals, where one is a referential extension of the other. This might thus still mean, as a reviewer also proposes, that proxy control and metonymic extension both instantiate distinct sub-types of a more general underlying class of referential extension allowed in grammar.
}

${ }^{9}$ See Rizzi (1986) for comparable minimal pairs in Italian. 
But proxy control sentences in Italian (19a) and German (19b) are readily compatible with episodic temporal adverbials, showing that a proxy control reading is possible in the absence of genericity:

a. Ieri la maestra $i$ ha chiesto al contadino $j$ [di EC $_{\text {proxy( } i)}$

yesterday the teacher has asked the farmer to

poter accarezzare l'asino].

may.INF pet.INF the donkey

'Yesterday, the teacher ${ }_{i}$ asked the farmer [to $\mathrm{EC}_{\text {proxy(i) }}$ pet the donkey].'

b. Gestern haben die Eltern $i$ die Lehrerin $j$ gebeten, $\left[\mathrm{EC}_{\text {proxy(i) }}\right.$ die yesterday have the parents the teacher asked the Hausaufgaben etwas später abgeben zu dürfen]. homework bit later hand.in.INF to may.INF 'Yesterday, the parents ${ }_{i}$ asked the teacher ${ }_{j}$ [for permission (for their children $\left._{\text {proxy(i) }}\right) \mathrm{EC}_{\text {proxy(i) }}$ to hand in the homework a bit late].'

Second, impersonal subjects like Italian si or German man 'one' may anaphorically refer to $\mathrm{PRO}_{a r b}$ :
a. È difficile [ $\mathrm{PRO}_{a r b}$ essere solar-i [quando $\mathrm{si}_{a r b}$ vuole]]. is difficult be.INF cheerful-M.PL when one wants 'It's difficult [ $\mathrm{PRO}_{a r b}$ to be cheerful [whenever one ${ }_{a r b}$ wants to]].'
b. Es is schwer [ $\mathrm{PRO}_{a r b}$ fröhlich zu sein [wann $\operatorname{man}_{a r b}$ will]]. it is heavy cheerful to be.INF when one wants 'It's difficult [ $\mathrm{PRO}_{a r b}$ to be cheerful [whenever one $\mathrm{arb}_{\text {rb }}$ wants to]].'

But for all our consultants, such impersonal subjects may not anaphorically refer back to a proxy controlled null subject; no amount of pragmatic coercion seems to improve such sentences for such speakers:

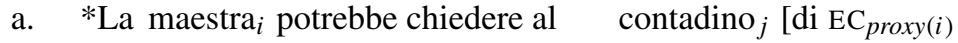
the teacher could ask.INF to.the farmer $\mathrm{C}$ poter accarezzare l' asino [quando $\operatorname{si}_{\text {proxy }(i)}$ vuole]]. may.INF pet.INF the donkey when one wants Intended: 'The teacher ${ }_{i}$ could ask the farmer ${ }_{j}$ [for permission (for the students $\left._{\text {proxy }(i)}\right) \mathrm{EC}_{\text {proxy }(i)}$ to pet the donkey [whenever one $\mathrm{proxy}_{(i)}$ wants to]].'

b. *Die Eltern ${ }_{i}$ könnten die Lehrerin ${ }_{j}$ bitten, [EC $_{\text {proxy(i) }}$ die the parents could the teacher ask.INF the Hausaufgaben abgeben zu dürfen [wann $\operatorname{man}_{a r b}$ will]]. homework hand.in.INF to may.INF when one wants

Intended: 'The parents ${ }_{i}$ could ask the teacher ${ }_{j}$ [for permission (for the children proxy $(i)) \mathrm{EC}_{\text {proxy(i) }}$ to hand in the homework [whenever one $_{\text {proxy }(i)}$ wants to]].'

Proxy control may thus fail to hold even when the conditions for arbitrary control, namely genericity and the presence of an impersonal subject, are met. We thus conclude that proxy control cannot be treated as a pragmatically restricted variant of arbitrary control. 


\subsubsection{Proxy control vs. partial control}

The fundamental difference between partial and proxy control is that, with partial control, the extension of the controller is properly included in that of the controllee $(i \rightarrow i+$ ); with proxy control, the set of individual(s) denoted by the controller does not properly include the controller. At the same time, both types of control have in common that the extension of the controllee is non-identical, but nevertheless pragmatically related, to that of the controller. It thus makes sense to ask whether the connection between them runs deeper, such that one is derivative of the other.

Indeed, a close examination reveals a one-way implicational relationship between proxy and partial control. Sentences like (22) (adapted from Landau 2013, 164) illustrate that it is possible to get partial control in the absence of proxy control:

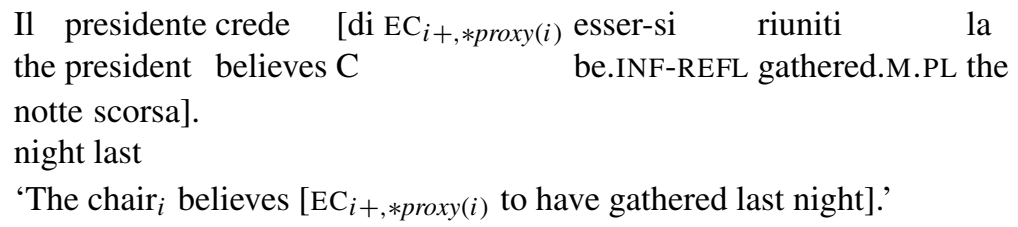

A proxy control reading is ruled out in (22) since 'believe' is not associated with a permission modality. The embedded predicate 'gather' adds the further restriction that the controller be included in the set of members denoted by the controllee. Thus, (22) must involve partial control and not proxy control. Crucially, however, the reverse does not seem to be the case. All speakers who allowed proxy control with a given predicate also allowed partial control with that predicate, once we tweaked the discourse-context to allow such a reading. Conversely, while a partial control reading could be pragmatically ruled out, under a given predicate, to yield an exclusively proxy control reading, such an exclusion doesn't seem possible semantically (or lexically). ${ }^{10}$

We take this to mean that the environments that license proxy control are a proper subset of those that license partial control. Not unexpectedly, given this, the predicates that license proxy control, at least those tested so far, also seem to be a proper subset of those predicates that have been shown to license partial control, e.g.: factive regret, surprised, hate, shocked, attitudinal believe, think, imagine, deny, desiderative want, prefer, yearn, refuse and interrogative wonder, ask, interrogate, inquire. ${ }^{11}$ The existence and properties of this asymmetric relation will end up directly shaping our analysis of proxy OC vs. NOC in subsequent sections (see, in particular, Sects. 4.2.3, 6.1, and 7.1.3).

Finally, an anonymous reviewer points out that, for them, and for some other native German speakers that they consulted, proxy control is only available for

\footnotetext{
${ }^{10}$ What remains to be checked in future research is how systematic this relation is by testing a broader range of partial control predicates with speakers allowing proxy control readings.

${ }^{11}$ An anonymous reviewer points out that this correlation between partial and proxy control dependencies entails that variation for proxy control should closely model variation for partial control in being independent of dialect boundaries and involving a great deal of intra-speaker variation. While it is not the aim of this paper to focus on the correlation between partial and proxy control, initial evidence suggests that the latter point does, at least, seem to be true (cf. Sect. 4.2 .3 for more).
} 
sentences that independently also allow partial control. Interestingly, furthermore, they cannot get proxy control for sentences that do not independently allow a forPP addition (as in: "Maria $i_{i}$ asked the teacher (for Gianni ${ }_{\text {proxy }(i)}$ ) $\mathrm{EC}_{\text {proxy }(i)}$ to pet the donkey"), suggesting that, for these speakers, there may be multiple routes to proxy control: one involving "true proxy control" with semantic extension, as we will propose, and another involving "fake proxy control" (in analogy with fake partial control as in Pitteroff et al. 2017b) involving exhaustive $\operatorname{proxy}(i) \rightarrow \operatorname{proxy}(i)$ control between a nominal in the PP and the controllee. We discuss this further in Sect. 4.2.3.

\subsection{Summary of proxy control}

Given the discussion so far, proxy control emerges as a genuinely new form of control in grammar that is irreducible to other, more familiar, referential dependencies (control or otherwise). Based on the discussion, we define proxy control as in (23):

Generalized proxy control (OC and NOC) relation:

a. For any two sets of individuals $i$ and $j$, where $i$ is a core participant in a permission-seeking or -granting speech-event $e_{1}$ and $j$ is a core participant in $e_{2}$, an eventuality that is consistent with permission being granted in $e_{1}, j=\operatorname{proxy}(i)$ iff:

(i) in $e_{1}, i$ acts on behalf of $j$;

(ii) in $e_{2}, j$ stands in for $i$;

(iii) $i$ and $j$ are directly associated through some discourse-salient group or activity.

b. In cases of proxy control, if a controller denotes $i$ and the controllee denotes $j, j=\operatorname{proxy}(i)$.

\section{Variation for proxy control: Distribution and diagnostics}

As mentioned at the outset, the proxy control data in this paper stems from the judgments of 46 native speakers divided across German (= 37 speakers) and Italian (=9 speakers). The data is further bolstered by the judgments of one of us, who is a native speaker of Bavarian-based Standard German and a southern Tuscany variety of Italian. Our German data was gathered via two surveys involving an online questionnaire conducted amongst a wider pool of consultants and face-to-face elicitations, additionally conducted among a smaller subset of these, to nail down more fine-grained judgments. Our German speakers spoke a range of dialects, primarily Bavarian-Swabian, Swabian, Bavarian, Austrian, and Saxonian, while our Italian speakers primarily spoke varieties of Italian from the Grosseto province (southern Tuscany). We tie no causal relation to those dialects given that there were also speakers from those areas that did not exhibit the same behavior. For the rest of the paper, we use "German" and "Italian" as cover-terms for these languages without attempting to narrow them down further in terms of dialect or idiolect. 
There is a wide range of intra- and inter-speaker variation in the acceptability and nature of proxy readings in German and Italian. ${ }^{12}$ The two main parameters of speaker-variation observed among our German and Italian consultants, involve: (i) whether a proxy reading for control sentences is available at all and (ii) whether proxy control is judged to be a species of OC or NOC. ${ }^{13}$ We tabulate these results with a two-by-two variation grid, as schematically presented in Table (24):

Schema of speaker types

\begin{tabular}{l|l|l}
\hline & $\checkmark$ PROXY & $\boldsymbol{X}$ PROXY \\
\hline OC & PROXY OC SPEAKERS & NON-PROXY OC SPEAKERS \\
NOC & PROXY NOC SPEAKERS & NON-PROXY NOC SPEAKERS \\
\hline
\end{tabular}

a. PROXY OC SPEAKERS accept proxy readings with proxy control predicates and pass OC diagnostics (i.e. fail NOC diagnostics);

b. NON-PROXY OC SPEAKERS pass OC diagnostics with proxy control predicates, but do not accept proxy control readings with those predicates;

c. PROXY NOC SPEAKERS accept proxy control readings but fail OC diagnostics with proxy control predicates;

d. NON-PROXY NOC SPEAKERS fail OC diagnostics but nonetheless reject proxy control readings under proxy control predicates.

\subsection{Availability of proxy control}

Turning to the first major parameter of variation, a number of orthogonally distinct grammatical factors condition the availability of proxy control for our consultants. Some of our consultants (23 out of 37 German; 3 out of 9 Italian) disprefer a control dependency, preferring instead a finite 'whether'-clause, with the proxy or impersonal subject being overtly expressed. For others, proxy control was only available under the concomitant presence of an overt permission nominal in the scope of the (permission-seeking or -asking) control predicate, with some even rejecting the sentences outright when this was absent. An anonymous reviewer notes a further point of variation for German, having to do with whether the referent of the (silent) proxy

\footnotetext{
${ }^{12}$ This is far from surprising, given how nuanced and delicate the judgments in question are. A similar range of variation has been noted for other types of control dependency, particularly for NOC which has proven to resist categorical judgments across populations. White and Grano (2014) show that even in English, where there is general consensus in the literature on the availability of partial control, there is a continuum of acceptability with respect to the membership of partial control predicates. Pitteroff et al. (2017b) illustrate that German involves even greater variation arguing that there are two routes to partial control in the language - one mediated by the properties of the control predicate, and one having to do with the properties of the embedded one. The variation for proxy control also cannot be dismissed as statistical "noise": our consultants are all native-speakers who performed reliably with grammatical and ungrammatical controls from our online survey and face-to-face acceptability tasks. The mere existence of speaker-variation for proxy control should, thus, by no means be taken to suggest that proxy control is not "real".

${ }^{13}$ Note that the possibility of a proxy oc interpretation is predicted, given that: a. the availability of proxy control under a given predicate entails that of partial control and $b$. partial control itself constitutes a type of OC.
} 
controllee is overtly expressed in the embedding clause with a 'for'-phrase, as in $(25):^{14}$

$$
\begin{aligned}
& \text { Die Lehrerin }{ }_{i} \text { hat für die Kinder } \text { proxy }(i)^{\text {den Bauern }} \text { (darum) gebeten } \\
& \text { the teacher has for the kids ther that.for asked } \\
& {\left[\mathrm{EC}_{\text {proxy }(i)}\right. \text { den Esel streicheln zu dürfen]. }} \\
& \text { the donkey pet.INF to may.INF }
\end{aligned}
$$

'The teacher ${ }_{i}$ asked the farmer ${ }_{j}$ on behalf of the kids [for permission $\mathrm{EC}_{\text {proxy(i) }}$ to pet the donkey].'

The reviewer further observes that, for some German speakers they in turn consulted, proxy control was only licit with predicates which at least optionally allow for an overt for-phrase along the lines of (25).

A consistent parameter of speaker variation involves the identity of the controlling and controlled predicates, in a proxy control sentence. For instance, some of our consultants dispreferred 'permit', others 'promise', as the embedding predicate. One speaker doubted they could get the intended readings if the controlled predicate is a predicate of personal experience, such as 'listen (to a lecture)'. As observed earlier, the existence of such variation should not surprise us: what is important for our purposes is that there are significant populations that $d o$ systematically accept proxy control sentences. ${ }^{15}$

\subsection{The OC vs. NOC distinction for proxy control}

The second major parameter of speaker variation, among our proxy consultants, had to do with whether the proxy control reading was interpreted as OC or NOC. We define all instances of OC in terms of the OC signature in (26), from (Landau 2013, 33):

\section{THE OC SIGNATURE:}

In a control construction $\left[. . \mathrm{X}_{i} . .\left[S \mathrm{PRO}_{i} ..\right] ..\right]$, where $\mathrm{X}$ controls the PRO subject of the clause $S$ :

a. The controller(s) X must be (a) co-dependent(s) [argument or adjunct] of $\mathrm{S}$.

b. PRO (or part of it) [this caveat subsumes cases of partial control as a sub-species of $\mathrm{OC}]$ must be interpreted as a bound variable.

\footnotetext{
${ }^{14}$ The addition of a for-phrase is an option with some, but not all, proxy control predicates in Italian, e.g. chiedere 'ask' and richiedere 'ask, demand'. But none of our Italian consultants required its presence or expressed a strong preference for its inclusion.

${ }^{15}$ In the face-to-face elicitations, on a scale going up from 1 to 5 , the judgments ranged from a mean of 4.56 ( standard deviation $(\mathrm{SD})=.46$ ) for sentences with bitten ('ask'), to a mean of 4.17 ( $\mathrm{SD}=1.27$ ) for the sentences with versprechen ('promise'). In the online survey, the sentences received lower judgments than in the face-to-face elicitations, ranging from $2.93(\mathrm{SD}=1.64)$ with bitten 'ask', to $2.33(\mathrm{SD}=1.47)$ with versprechen 'promise' - again all out of 5 , to be compared to grammatical fillers at 4.59 , and ungrammatical fillers at 1.37 . We suspect that the difference between the two formats is due to the fact that in the face-to-face elicitations consultants had the possibility to clarify context when needed, while this was not an option in the online survey.
} 
NOC, in contrast, is understood as an Elsewhere (see Hornstein 1999; Landau 2015a; McFadden and Sundaresan 2018, among many others): it can but need not be a codependent of its controller, and can but need not be interpreted as a bound variable. The interpretations available to the controllee under OC are thus a proper subset of those available to it under NOC and can be empirically tested with respect to the syntactic and semantic diagnostics below:

Empirical diagnostics - OC vs. NOC:

\begin{tabular}{l|l|l}
\hline & OC PRO & pro \\
\hline Coreference w. controller & Yes & Yes or No \\
Strict/Sloppy under ellipsis & Sloppy & Strict or Sloppy \\
de se/de re in attitude contexts & de se & de se or de re \\
\hline
\end{tabular}

The majority of our German and Italian consultants qualified as PROXY NOC speakers, with a smaller number qualifying as PROXY OC speakers. For our PROXY OC speakers, proxy control was only licit if it involved a local, c-commanding controller, and the controllee was interpreted obligatorily de se in attitude contexts. In addition, as we later discuss in Sect. 4 and Sect. 8.2, even for such speakers, certain configurations could trigger them to switch to an NOC parse for a given proxy control sentence. $^{16}$

For our PROXY NOC speakers, these diagnostics did not designate necessary input conditions for proxy control (cf. Sect. 3.2), in line with the idea that NOC represents an Elsewhere scenario. Some of these speakers had mixed judgments with respect to OC vs. NOC diagnostics-e.g. disallowing strict readings under ellipsis of the controlled clause (with exhaustive, partial, and proxy interpretations) while also allowing non-local antecedents for these same interpretations. Others demonstrated more uniform judgments, with e.g. the possibility of non-local antecedence going hand-in-hand, for them, with the availability of strict readings under ellipsis. These same speakers, however, disallowed strict readings under ellipsis for control complements under classic OC predicates like 'want' and 'try', suggesting that, while such predicates are unanimously judged OC, others like 'ask' show speaker-variation with respect to whether they select an OC or NOC structure. In some instances, both options were available and speakers varied amongst themselves with respect to which one they choose, based on extra-grammatical factors.

Below, we walk through the diagnostics for proxy OC vs. proxy NOC in greater detail, with illustrative examples from German and Italian.

\subsubsection{Proxy controller must be co-dependent of control clause}

For proxy OC speakers, the controller must be an argument of the predicate that directly embeds the control clause. Cyclic control or true long-distance control across multiple clauses are thus disallowed, as illustrated by (29) under the scenario in (28):

\footnotetext{
${ }^{16}$ In Sect. 4, we present evidence to argue that this is reflective of true intra-speaker variation: in spite of the availability of NOC in these special contexts, NOC is not available to these speakers in regular proxy control sentences.
} 
(28) Potential proxy-proxy scenario: There is a donkey next to the elementary school. The teacher's kids would like to pet it. The teacher, who is sick at home today, asks her husband if he could do her the favor of stopping by and asking the farmer if the kids are allowed to pet the donkey.

La maestra ma pregato suo marito $_{i}\left[\mathrm{di} \mathrm{EC}_{i, * j, * k}\right.$ chiedere al
the teacher has asked her husband C ask.INF to.the
contadino $_{j}[\mathrm{di} \mathrm{EC} \# \operatorname{proxy}(i), * \operatorname{proxy}(k)$ poter accarezzare l' asino]].
farmer C may.INF pet.INF the donkey

'The teacher asked her husband to ask the farmer for permission to pet the donkey.'

The matrix subject denoting the teacher is a direct associate of the controlled subject, but fails to satisfy the syntactic locality restriction on OC. The intermediate subject denoting the teacher's husband satisfies the locality condition but (pragmatically) fails to satisfy the condition of being a direct associate of the individuals denoted by the proxy controllee. ${ }^{17}$ The proxy reading in (29) is thus categorically rejected by our proxy OC speakers. Parallel tests for German yield identical results.

\subsubsection{Bound variable status of controllee}

A bound variable is predicted to yield only sloppy readings under ellipsis, but a deictic form is compatible with both strict and sloppy readings under these conditions (Reinhart 1983). Cases of OC, where the controllee is interpreted as a bound variable, should thus yield only sloppy readings under ellipsis. This was confirmed for our PROXY OC speakers.

Our PROXY OC Italian speakers deemed the proxy control sentence in (30) to be acceptable only under the sloppy reading in (30a), where the teacher asked the farmer for her (the teacher's) students to pet the donkey and the teacher's husband asked the farmer for his (the husband's) students to pet the donkey. The strict reading in (30b) where the teacher asks for the teacher's students, and the husband also asks for the teacher's students to pet the donkey—was considered to be unacceptable: ${ }^{18}$

$$
\begin{aligned}
& \text { La maestra }{ }_{i} \text { ha pregato il contadino } j\left[\mathrm{di} \mathrm{EC}_{\text {proxy }(i)}\right. \text { poter accarezzare } \\
& \text { the teacher has asked the farmer } \mathrm{C} \text { may.INF pet.INF } \\
& \mathrm{l} \text { ' asino] e suo marito } k \text { uguale } \ldots\left[\mathrm{EC}_{\operatorname{proxy}(k), * \operatorname{proxy}(i)] .}\right. \\
& \text { the donkey and her husband too } \\
& \text { 'The teacher asked the farmer for permission to pet the donkey and her hus- } \\
& \text { band, too.' }
\end{aligned}
$$

\footnotetext{
${ }^{17}$ As expected, the sentence becomes grammatical under a different discourse scenario, e.g. by interpreting the teacher's husband himself as a direct associate of the kids. This might be the case if he is also a teacher at the same school, for instance.

${ }^{18}$ The only way to get a strict reading is if the extension of $\operatorname{proxy}(i)$ and $\operatorname{proxy}(j)$ happened to be extensionally equivalent - e.g. if both the teacher and her husband happened to teach in the same elementary school, thus had the same students; but this would, of course, be nothing but an instance of accidental coreference.
} 
a. Sloppy READING: The teacher $i$ asked the farmer for permission for the teacher's students proxy $(i)$ to pet the donkey and the teacher's husband $_{k}$ asked for permission for the husband's students proxy $(k)$ to pet the donkey, too.

b. STRICT READING: The teacher ${ }_{i}$ asked the farmer for permission for the teacher's students proxy $(i)$ to pet the donkey and the teacher's husband $k$ asked for permission for the teacher's students proxy $(i)_{\text {to }}$ to pet the donkey, too.

\subsubsection{No "sub-group" control}

Given that OC is syntactically constrained (while NOC is not), we predict that OC alone should disallow "sub-group control": i.e. control which excludes one or more conjuncts of a conjoined controller. The conjoined phrase as a whole must serve as the controller, and not individual conjuncts inside this phrase, since the former alone c-commands the controllee, as illustrated for English below:

"Sub-group control" as a diagnostic for OC vs. NOC:

a. OC: Hansel $_{i}$ and $\mathrm{Gretel}_{j}$ wanted $\left[\mathrm{EC}_{i+j, * i, * j}\right.$ to eat pizza].

$\boldsymbol{X} \approx[$ Hansel and Gretel] wanted Hansel to eat pizza.

$\boldsymbol{x} \approx$ [Hansel and Gretel] wanted Gretel to eat pizza.

$\checkmark \approx[$ Hansel and Gretel ] wanted Hansel and Gretel to eat pizza.

b. NOC: Hansel $_{i}$ and Gretel $_{j}$ thought that it would be a shame $\left[\mathrm{EC}_{i, j, j+k, l}\right.$ to give up now].

$\checkmark \approx[$ Hansel and Gretel] thought that it would be a shame for Hansel to give up now.

$\checkmark \approx$ [Hansel and Gretel] thought that it would be a shame for Gretel to give up now.

$\checkmark \approx[$ Hansel and Gretel $]$ thought that it would be a shame for Hansel and Gretel to give up now.

$\checkmark \approx$ [Hansel and Gretel] thought that it would be a shame for someone else to give up now.

We now predict that if proxy control is a species of NOC, sub-group control should be licit, just as in (31b); if it is a species of oc, it should be ruled out, as in (31a). We tested this for the proxy control Italian example in (33) under the scenario in (32):

(32) Proxy scenario: Gianni is a prison inmate. Gianni's wife and an attorney (who himself has no association with Gianni) are petitioning the prisonwarden for a group of people, involving some combination of these individuals and/or potentially others, to meet.

$\left[\mathrm{L}^{\prime} \text { avvocato }_{i} \text { e la moglie }\right]_{k}$ hanno pregato il secondino $l$ [di

the attorney and the wife have asked the warden $\mathrm{C}$

$\mathrm{EC}_{k, k+, \operatorname{proxy}(k)}$ poter-si incontrare in privato].

can.INF-REFL meet.INF in private 
'The attorney and the wife asked the warden for permission to meet in private.'

For proxy OC Italian speakers, the following readings are licit for (33):

$\checkmark$ Exhaustive control $(k \rightarrow k)$ :

$\approx[$ The attorney and wife $]$ asked for the attorney \& wife to meet.

$\checkmark$ Partial control $(k \rightarrow k+)$ :

$\approx[$ The attorney and wife $]$ asked for the attorney \& wife \& Gianni to meet.

$\checkmark$ Proxy control $(k \rightarrow \operatorname{proxy}(k))$ :

$\approx[$ The attorney and wife $]$ asked for the attorney \& wife's mutual friends to meet.

However, sub-group partial control and sub-group proxy control are ruled out:

$\boldsymbol{x}$ Partial sub-group control: $\approx$ [The attorney and wife ] asked for the wife \& Gianni to meet.

$\boldsymbol{x}$ Proxy sub-group control: $\approx$ [The attorney and wife] asked for Gianni \& his fellow-inmates to meet.

This is clear evidence that c-command is a requirement on proxy control (as for partial control) for our proxy OC Italian speakers. Identical judgments hold for analogous German proxy sentences for German PROXY OC consultants.

\subsubsection{Obligatory de se}

Our PROXY OC consultants also judged the proxy attitude report under a proxy control predicate to be obligatorily de se. Consider the proxy control sentence in German (34):

$$
\begin{aligned}
& \mathrm{Maria}_{i} \text { hat } \mathrm{Susan}_{j} \text { gebeten [PRO proxy(i) früher gehen zu dürfen]. } \\
& \text { Maria has Susan asked earlier go.INF to may.INF }
\end{aligned}
$$

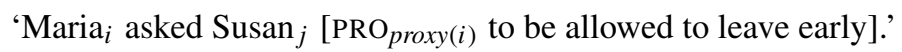

Speakers were asked to evaluate (34) under two distinct scenarios. In the de se scenario in (35), Maria is aware that the team-members she is asking permission for are her own. The controlled clause in (34) is here thus understood as a first-person (de se) attitude report by Maria:

(35) De se Scenario: Maria is a lead engineer at a software company. This past week, she and the team she leads worked late hours to meet a deadline. The deadline has now been successfully met, so Maria asks her boss, Susan: "Can my team-members leave early today?" Maria herself must unfortunately stay late today to log the team report.

In the de re scenario in (36), Maria herself is unaware that Team 5 is her own team. The controlled clause in (34) thus represents a third-person (de re) attitude report by Maria. Note that (36) still supports a proxy control relation between Maria and her teammates in (34) because Team 5 is directly associated with Maria by virtue of being her own team. 
De re Scenario: Maria is a lead engineer at a software company. This past week, all the software teams, including the team Maria leads, have been working late hours to meet a deadline. On the anonymized performance sheet, Maria sees that Team 5 worked the longest hours. The deadline has now been successfully met, so Maria asks her boss, Susan: "Can Team 5 leave early today?" What Maria doesn't realize is that Team 5 is her own team. Incidentally, Maria knows that she herself will have to stay late today.

Our PROXY OC consultants in German unanimously judged (34) to be false under the de re scenario in (36) and true under the de se one in (35). Identical judgments were obtained for analogous sentences in Italian from our Italian proxy OC speakers.

\subsection{Distribution of proxy control in German}

Using our German consultants as illustration, we now discuss our methodology of data collection, and describe the resulting distribution of proxy control with respect to the diagnostics above.

\subsubsection{A brief description of methodology}

Our proxy control data for German was gathered from a sample of 37 native speakers, predominantly from Germany, but also from Austria and Switzerland. 27 German speakers were tested via an online questionnaire and the remaining 10 were evaluated via face-to-face judgment tasks. For the questionnaire, speakers were asked to evaluate the grammaticality of a target sentence, involving different types of control, on a discrete scale of 1 (bad) to 5 (perfect). Each target sentence was accompanied by a detailed discourse scenario which was designed to influence a particular interpretation of the controlled subject. For the face-to-face judgment task, we first read the target sentence aloud and asked our consultants to evaluate its grammaticality out of the blue, i.e. without an accompanying discourse scenario. We then asked our speakers to re-evaluate these sentences along the five-point scale, against dedicated discourse-scenarios: this allowed us to tease apart the role of pragmatic conditioning in the grammaticality judgments.

For both surveys, our target sentences were designed to answer two questions: (i) do speakers accept proxy control readings?, and (ii) is there further variation in whether speakers judge proxy control as OC vs. NOC? Sentences (a)-(c) in (37) constituted the core types of target sentences. Sentence-types (a)-(d) used bitten ('ask') as the main control predicate:

a. Local: $\quad$ Sentence with a local, c-commanding controller.

b. Non-local: Sentence with a non-local, c-commanding controller.

c. Ellipsis: A control sentence with local controller conjoined with another local sentence with elided verb-phrase.

d. Condition B: A sentence with local controller \& an overt pronoun in the control complement which corefers with the controller. 
e. Permit-may: Sentence with local controller, 'permit' as the control verb, \& with the overt modal dürfen ('may') in the control complement.

f. Permit-bare: Sentence with local controller, 'permit' as the control verb, \& no overt dürfen ('may') in the control complement.

g. Promise: $\quad$ Sentence with local controller \& main control verb versprechen ('promise').

Each of the core sentence types in (a)-(c) above was evaluated under three different discourse scenarios, each favoring a distinct degree of exhaustification for the control relation in the target sentence: (i) Exhaustive scenario: favoring an exhaustive control reading $(i \rightarrow i)$; Partial scenario: favoring a partial control reading $(i \rightarrow i+)$; Proxy scenario: favoring a proxy control reading $(i \rightarrow \operatorname{proxy}(i))$. The sentence types in (d)(g) above were only presented under a proxy scenario. Ellipsis sentences in (c) were interpreted against a scenario that was amenable to a strict interpretation of the elided controllee.

We predicted that a speaker that allowed proxy control with an OC reading should give the following judgments. Sentences with local c-commanding antecedents should tend toward the maximum score of 5; sentences with non-local c-commanding antecedents, and those with a strict reading under ellipsis, on the other hand, should tend toward the minimum score of 1 . In contrast, we predicted that a speaker who judges proxy control sentences to have an NOC parse should judge sentences with non-local antecedents and strict readings under ellipsis as veering toward a perfect 5 . All other speakers should fall somewhere between these two end-points.

Following the logic that the mid-point of our five-point scale indicates mid-level acceptability or uncertainty, ${ }^{19}$ if a speaker allows proxy oC readings under proxy control predicates, the sentences with local c-commanding antecedents with proxy scenarios should be judged above the mid-point overall. Conversely, if a speaker generally disallows NOC parses for such sentences, the sentences which require an NOC structure to be felicitous (diagnosed via ellipsis with a context favoring a strict reading and non-local antecedents), should be judged below the mid-point overall. If speakers were to easily allow NOC structures for permission-seeking control sentences, then the mean of the sentences that should only be acceptable with an NOC structure should be in the upper half of the scale. Those sentences were the sentences where a strict reading under ellipsis was suggested, as well as those sentences that suggested a non-local antecedent. The sentence with a Condition B violating pronoun in the control complement could also have been included as a criterion for NOC, ${ }^{20}$ but it was omitted here in favor of keeping a clean yes-no binary opposition per defining property (proxy vs. no proxy; OC vs. NOC).

\footnotetext{
${ }^{19}$ For the online survey, the ungrammatical fillers had a mean value of 1.37 , the grammatical fillers a mean value of 4.59 .

${ }^{20}$ See Sect. 4.2.2 for discussion. In a nutshell, those sentences are accepted when an NOC structure is selected for the control complement; the conclusion is supported by sudden acceptance of strict readings under ellipsis.
} 


\subsubsection{Results from the survey: Speaker-variation for proxy control}

Based on the results, we classified our participants post-hoc into the following four groups: PROXY OC SPEAKERS, NON-PROXY OC SPEAKERS, PROXY NOC SPEAKERS, and NON-PROXY NOC SPEAKERS, as described in Table (38). The labels are based on the sentence types in (37); subscripts indicate exhaustive vs. partial vs. proxy scenarios, with all standing for exhaustive + partial + proxy.

Speaker-group criteria

a. PROXY OC SPEAKER

(i) $\operatorname{Mean}_{\left(\text {local }_{\text {proxy }} \text {; permit-may }\right.}^{\text {proxy }}$; permit-bare proxy $_{\text {; }}$ promise $_{\text {proxy }}$ ) $>3$

(ii) $\operatorname{Mean}\left(\right.$ ellipsis $_{\text {all }} ;$ non-local $\left._{\text {all }}\right)<3$

b. NON-PROXY OC SPEAKER

(i) Mean $_{\left(\text {local }_{\text {proxy }} \text {; permit-may }\right.}$ proxy ; permit-bare proxy $_{\text {; }}$ promise $_{\text {proxy }}$ ) $\leq 3$

(ii) Mean(ellipsis all $_{\text {; non-local }}$ all $)<3$

c. PROXY NOC SPEAKER

(i) $\operatorname{Mean}\left(\right.$ local $_{\text {proxy }}$; permit-may proxy $_{\text {; }}$ permit-bare proxy $_{\text {; }}$ promise $_{\text {proxy }}$ ) $>3$

(ii) Mean(ellipsis all $;$ non-local all $) \geq 3$

d. NON-PROXY NOC SPEAKER

(i) Mean(local proxy $_{\text {; }}$ permit-may proxy $_{\text {; }}$ permit-bare proxy $_{\text {; }}$ promise $_{\text {proxy }}$; ellipsis $_{\text {proxy }}$; non-local proxy $\left._{1}\right) \leq 3$

(ii) $\operatorname{Mean}\left(\right.$ ellipsis $_{\text {all }} ;$ non-local $\left._{\text {all }}\right) \geq 3$

Based on both our online and in-person-surveys, 5 speakers (14\%) classified as PROXY OC SPEAKERS, and 9 speakers (24\%) as PROXY NOC SPEAKERS; the remaining 23 were 7 NON-PROXY OC SPEAKERS (19\%), and 16 NON-PROXY NOC SPEAKERS $(43 \%)$.

Table 1 shows mean ratings per sentence type per speaker group, on a scale of 1 (bad) to 5 (perfect), for both survey types.

The differences between the populations, as well as the logic of the diagnostics for OC vs. NOC are visible as clear trends in the table's data summary. Rows 3-6, which represent the proxy control sentences that are compatible with OC, support the idea that there is a population of PROXY (OC and NOC) SPEAKERS that contrasts with a population of NON-PROXY SPEAKERS: the former give much higher judgments for these sentences than the latter. The distinction between OC and NOC SPEAKERS becomes visible in rows 7-12, which represent sentences that are only acceptable under an NOC parse. In both surveys, PROXY OC and NON-PROXY OC speakers judged these sentences to be clearly worse than did their NOC counterparts. ${ }^{21}$ The data above

\footnotetext{
${ }^{21}$ The non-local sentence with a partial control context received strikingly good ratings from all speaker groups in the online survey. This is unexpected for PROXY OC and NON-PROXY OC SPEAKERS (5.00/4.17) since these structures are predicted to be good only in case of an NOC parse. But this might be due to the fact that the context did not clearly exclude the local antecedent from the controllee's reference, possibly allowing for a partial control reading that included both the local and the non-local controller.
} 
Table 1 Mean ratings per speaker group per survey

\begin{tabular}{|c|c|c|c|c|c|c|c|c|}
\hline & \multicolumn{4}{|c|}{ Online survey } & \multicolumn{4}{|c|}{ Face-to-face elicitations } \\
\hline & PROXY & NON-PROXY & PROXY & NON-PROXY & PROXY & NON-PROXY & PROXY & NON-PROXY \\
\hline & OC (2) & oc $(6)$ & NOC (5) & NOC (14) & OC (3) & OC (1) & NOC (4) & NOC (2) \\
\hline 1. local exh & 5.00 & 5.00 & 4.80 & 4.86 & 5.00 & 5.00 & 5.00 & 5.00 \\
\hline 2. local prt & 5.00 & 4.67 & 3.40 & 4.93 & 5.00 & 5.00 & 5.00 & 5.00 \\
\hline 3. local prx & 5.00 & 1.33 & 4.40 & 2.79 & 4.50 & 5.00 & 4.75 & 4.25 \\
\hline $\begin{array}{l}\text { 4. permit-bare } \\
\text { prx }\end{array}$ & 3.00 & 1.17 & 2.80 & 1.79 & 3.33 & 1.00 & 2.75 & 2.00 \\
\hline $\begin{array}{l}\text { 5. permit-may } \\
\text { prx }\end{array}$ & 5.00 & 2.33 & 3.80 & 2.14 & 4.00 & 2.00 & 4.25 & 3.75 \\
\hline 6. promise prx & 5.00 & 1.50 & 3.60 & 1.86 & 4.67 & 3.00 & 4.25 & 3.25 \\
\hline $\begin{array}{l}\text { 7. non-local } \\
\text { exh }\end{array}$ & 3.00 & 2.00 & 4.40 & 3.21 & 3.00 & 5.00 & 5.00 & 5.00 \\
\hline 8. non-local prt & 5.00 & 4.17 & 4.80 & 4.57 & 3.17 & 3.00 & 5.00 & 5.00 \\
\hline $\begin{array}{l}\text { 9. non-local } \\
\text { prx }\end{array}$ & 1.00 & 1.33 & 4.00 & 3.36 & 2.17 & 3.00 & 4.25 & 3.00 \\
\hline $\begin{array}{l}\text { 10. strict-ellipsis } \\
\text { exh }\end{array}$ & 2.00 & 3.33 & 4.40 & 4.00 & 2.17 & 1.00 & 4.88 & 4.00 \\
\hline $\begin{array}{l}\text { 11. strict-ellipsis } \\
\text { prt }\end{array}$ & 2.00 & 2.83 & 4.00 & 4.29 & 2.33 & 1.00 & 4.75 & 3.75 \\
\hline $\begin{array}{l}\text { 12. strict-ellipsis } \\
\text { prx }\end{array}$ & 2.00 & 1.00 & 4.40 & 2.64 & 2.67 & 1.00 & 4.25 & 3.75 \\
\hline
\end{tabular}

shows that PROXY NOC SPEAKERS outnumber PROXY OC SPEAKERS in German (this was also true in Italian).

\section{Genuine cases of proxy OC vs. NOC must be structurally distinct}

The standard wisdom (see e.g. Boeckx et al. 2010; Landau 2015b: as well as prior joint work by one of us in McFadden and Sundaresan 2018) is that the empirical differences between OC and NOC (cf. Sect. 3.2) stem from underlying syntactic differences between them. Abstracting over points of detail for now, the main idea is that, in cases of OC, the controllee and controller are related through a syntactic dependency, explaining why OC is subject to syntactic restrictions. Wurmbrand (2001, 2002), Landau (2013), McFadden and Sundaresan (2018, a.o.) further argue that oc itself can be derived in two ways. In more tightly constrained variants of oC-involving e.g. sequence-of-tense or -mood, and obligatorily exhaustive readings, as under 'try'-class predicates - the controlled clause is not a (strong) phase, allowing a direct syntactic relation between the controller and controllee (cf. Ex. 39)). But in cases of OC which are temporally, modally and referentially less restricted, the controlled clause instantiates a (strong) CP phase. Given standard assumptions about phase locality (Chomsky 2000, 2001), this entails that the controller and controllee in such cases can only syntactically communicate via a phase-peripheral element of the controlled clause, e.g. the phasal $\mathrm{C}$ head, yielding a mediated syntactic dependency, as in Ex. (40). 
With genuine cases of NOC, in contrast, Kuno (1975), Frascarelli (2007), Boeckx et al. (2010), Landau (2015b), McFadden and Sundaresan (2018, among many others) propose that the controllee is syntactically related to a silent pronominal operator, denoting logophoricity or topicality, at the edge of the controlled clause (see again, Ex. (41)). This pronominal operator then refers to the controller discourse-pragmatically. There is thus no syntactic relationship between the controller and controllee in cases of NOC: the dependency between the two is mediated by the pronominal operator in the periphery of the controlled clause. Finally, in cases where the controllee enters into no syntactic dependency whatsoever, we get an arbitrary control reading by default, as in Ex. (42). These variants are schematized below (McFadden and Sundaresan 2018, Exx. 87-91:49):

\section{Exhaustive oC (direct Agree)}

a. Marie $_{i}$ tried $\left[\mathrm{EC}_{\{i, * j\}}\right.$ to guzzle the beer].

b. DP V [ EC ...]

(40) Mediated oc (mediated Agree via C)

a. Marie $e_{i}$ wanted [ $C \mathrm{EC}_{\{i, * j\}}$ to guzzle the beer].

b. DP V [ C EC ...]

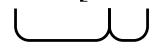

(41) Types of NOC

[ShiftP AboutnessTopic/Persp-Holder Shift ${ }^{0}[$ EC ... ] ]

(42) Arbitrary PRO: Agree fails yielding an arbitrary interpretation by default:

a. $\quad\left[\mathrm{EC}_{\{i, j\}}\right.$ To run out of hot sauce] would be embarrassing.

b. [PhaseBoundary....EC ...]

In Sect. 4.1, we present theoretical arguments showing that, if proxy oc and proxy NOC are genuinely distinct variants of proxy control, they must involve distinct syntactic structures corresponding to the schema above. Section 4.2 then empirically confirms that unambiguous cases of proxy NOC indeed have a distinct underlying structure that genuine cases of proxy OC must lack. Note that this does not (yet) constitute independent evidence that proxy OC is indeed genuine (we turn to this in Sect. 5): only that, if there are such cases of genuine proxy OC, they must have a distinct underlying structure from genuine cases of proxy NOC.

\subsection{Theoretical considerations: Proxy OC vs. proxy NOC}

In this section, we argue that assuming that proxy OC and proxy NOC have genuinely distinct syntactic structures (as in (39)-(42) above), comes with non-trivial consequences for the syntactic nature of the proxy controllee in each case. Our argument proceeds as follows:

(43) Syntactic properties of the proxy controllee in cases of proxy OC vs. proxy NOC:

(i) With genuine proxy OC, the controller-controllee relation is syntactic. 
(ii) With genuine proxy NOC, the controller-controlle relation is not syntactic, but discourse-pragmatic.

(iii) The $i \rightarrow \operatorname{proxy}(i)$ relation cannot be straightforwardly established in syntax.

$\therefore$ In genuine cases of proxy oc, if the controller has syntactic features corresponding to $i$, the controllee cannot bear syntactic features corresponding to $\operatorname{proxy}(i)$.

$\therefore$ In genuine cases of proxy NOC, if the controllee has syntactic features corresponding to $i$, the controllee can bear features corresponding to $\operatorname{proxy}(i)$.

\subsubsection{Theoretical implications for genuine proxy OC}

The two main theories of control within the Minimalist framework (Chomsky 2001, and subsequent) differ with respect to whether the syntactic dependency between the controller and controllee, in cases of OC, involves movement or the abstract Agree mechanism of feature-matching or feature-copying.

Under the movement theory of control (MTC) (Hornstein 1999, et seq.), OC is the result of (thematic) A-movement from the controlled to the controlling position. Cases of exhaustive OC are thus straightforwardly captured: the controller and controllee are identical by virtue of being the head and tail of the same A-chain. Instances of partial OC initially seem problematic for the MTC: after all, how can a nominal partially A-move from one position to another? One recent line of analyses within the MTC (e.g. Hornstein 2003; Rodrigues 2007; Słodowicz 2008; Boeckx et al. 2010; Sheehan 2012, 2014) proposes that partial control should be derived by having the controllee (the tail of the A-chain) associate with a null comitative PP in the control complement, yielding (abstracting over technical details for now), a structure like that in (45) for (44):

$\operatorname{Susan}_{i}$ agreed [PRO ${ }_{i+(j)}$ to meet this afternoon].

$\operatorname{Susan}_{i}$ agreed [[PRO $\left.\left.(\text { with [the others }]_{j}\right)\right]_{i+j}$ to meet this afternoon].

Partial OC is thus a composite of exhaustive OC involving A-movement of the controllee plus the associative reading contributed by the null comitative PP.

But such a syntactic analysis, to the extent that it is even a robust alternative for part-whole control relations, ${ }^{22}$ patently cannot be deployed to establish an $i \rightarrow \operatorname{proxy}(i)$ syntactic relation between the controller and controllee in cases of proxy OC. First, the $i \rightarrow \operatorname{proxy}(i)$ relation is not a comitative relation at all. Second, and perhaps more importantly, the extension of the controllee does not properly include that of the controller. For the MTC, this would essentially mean that the head

\footnotetext{
${ }^{22}$ Landau (2016) has argued that the null comitative analysis for partial control is incorrect (but see counter-arguments in Pitteroff and Sheehan 2018). As we have seen, it is predicated on the notion that the controllee is itself semantically singular and that the plurality associated with partial control comes out only due to its association with a null comitative PP. However, empirical tests for number involving reflexive binding and secondary predication, among others, suggest that the controllee must itself be underlyingly plural in these cases. We do not explore this further since it is incidental to the main concerns of this paper.
} 
and tail of the A-movement chain should be able to have different referents, with the head of the chain (instantiating the controller) bearing features denoting $i$ and the tail (instantiating the controllee) bearing features denoting $\operatorname{proxy}(i)$ where $\operatorname{proxy}(i)$ can explicitly exclude $i .^{23}$

A naïve modeling of oc based on Agree (in the sense of Landau 2004, for example) would have precisely the same problems in deriving $i \rightarrow \operatorname{proxy}(i)$, and for the same reasons. Nevertheless, we might imagine that OC involves a more complex multiple Agree relation. Such a scenario might involve the controllee probing, via upward Agree (see e.g. McFadden and Sundaresan 2018; Fischer 2018: for upward Agree-based treatments of OC and Wurmbrand 2014a; Bjorkman and Zeijlstra 2019 a.o. for general arguments that Agree can be upward), the controller $i$ as well as an implicit (but crucially syntactically represented) set of individuals proxy $(i)$. Such an Agree operation would trivially yield a $i \rightarrow i+$ partial control relation. However, we would still need a mechanism to remove the features pertaining to the controller $i$ from the whole. Alternatively, we might consider having the controllee Agree with the argument denoting the set of individuals $\operatorname{proxy}(i)$ alone. The controller denoting $i$ might be involved in mediating this relationship but would crucially not participate in feature-valuation. But it is not clear how this would actually be implemented without the addition of ad hoc rules to the Agree operation.

To sum up, then, assuming there is indeed a genuine case of proxy oc, the controllee in such cases cannot bear syntactic features corresponding to proxy $(i)$. Note again, however, that this by itself says nothing about whether such bonafide cases of proxy oc do indeed exist.

\subsubsection{Theoretical implications for genuine proxy NOC}

We have seen (Ex. (41)) that, in genuine cases of NOC, there is no syntactic dependency (direct or mediated) between the controller and controllee. Rather, the controllee Agrees with a silent pronominal operator in its own clause which then discourse-pragmatically refers to the controller.

Assuming that genuine cases of proxy NOC correspond to this template, this immediately frees the controllee in such cases from the challenges described for proxy OC. In a scenario where the pronominal operator itself bears features corresponding to $\operatorname{proxy}(i)$, Agree with the clausemate proxy controllee would result in the controllee also bearing features corresponding to $\operatorname{proxy}(i)$. This is the syntactic correlate of an exhaustive $\operatorname{proxy}(i) \rightarrow \operatorname{proxy}(i)$ relation. This pronoun will then refer to the controller denoting $i$ in the discourse-pragmatics, yielding the appearance of a hybrid $i \rightarrow \operatorname{proxy}(i)$ relation between the controller and controllee.

\footnotetext{
${ }^{23}$ An anonymous reviewer suggests that proxy OC might be derivable within the MTC by associating the controllee (tail of the A-chain) with a "for the proxy of" string (e.g. "Maria ${ }_{i}$ asked the farmer ${ }_{j}$ (for permission) [for the proxy of Maria $]_{p r o x y(i)}$ to pet the donkey"). But such an analysis is still unviable. Maria would need to move out of a complex subject, thereby violating conditions on subject-islandhood (Ross 1967: and the Specified Subject Condition of Chomsky 1973 a.o.). Furthermore, "for the proxy of" is not a constituent, thus also couldn't be added after A-movement of Maria. The proxy control data thus seems to pose a genuine challenge for movement based treatments of obligatory control.
} 


\subsection{Empirical confirmation}

In this section, we present empirical evidence from German and Italian confirming the theoretical predictions laid out in Sect. 4.1. Such evidence shows that, if the controllee in a proxy control sentence bears syntactic features corresponding to $\operatorname{proxy}(i)$, for a controller bearing features corresponding to $i$, then that sentence must instantiate an unambiguous NOC structure which differs from any genuine cases of proxy OC that correspond to the structural templates in (39)-(40),

\subsubsection{Floating quantifier agreement in Italian}

In Italian, a floating quantifier (FQs) associated with a subject bears overt $\phi$ agreement matching the $\phi$-features of the subject. FQs can thus be exploited to diagnose the $\phi$-features of a subject whose features are not otherwise visible on the surface, as with a silent subject controllee. Consider the Italian sentences below, interpreted against the scenario in (46):

(46) Scenario: A male teacher is leading a group of schoolgirls on a science retreat. They are staying at a hotel which only has room to accommodate a certain number of people for breakfast at a time. The teacher wants to ensure that they can all have breakfast together.

(47) a. (Quando noi ragazz-e ${ }_{j}$ della $4 \mathrm{~F}$ andiamo in gita), when we girls-F.PL of.the 4F go.1PL in excursion

il nostro maestr-o $\mathrm{O}_{i}$ chiede alla receptionist $\left[\mathrm{di} \mathrm{EC}_{i+}\right.$ poter the our teacher-M.SG asks to.the receptionist $\mathrm{C}$ may.INF fare colazione tutt-i insieme]. do.INF breakfast all-M.PL together

PARTIAL CONTROL: '(When [we girls] $j$ go on a school trip), [our teacher $]_{i}$ asks the receptionist for permission [to all $\mathrm{EC}_{i+j}$ have breakfast together].' (Literal)

b. $\%$ (Quando noi ragazz-e proxy(i) $_{\text {della }} 4 \mathrm{~F}$ andiamo in gita), when we girls-F.PL of.the 4F go.1PL in excursion

il nostro maestr- $\mathrm{o}_{i}$ chiede alla receptionist $\left[\mathrm{di} \mathrm{EC}_{\text {proxy }(i)}\right.$ the our teacher-M.SG asks to.the receptionist C

poter fare colazione tutt-e insieme]. may.INF do.INF breakfast all-F.PL together

PROXY CONTROL: '(When [we girls] proxy $(i)$ go on a school trip), [our teacher $]_{i}$ asks the receptionist for permission [to all $\mathrm{EC}_{\text {proxy(i) }}$ have breakfast together].' (Literal)

In (47a), the FQ associated with the controllee surfaces as tutti ('all.MPL') with resolved M.PL agreement: mixed $\mathrm{m}+\mathrm{f}$ gender (here corresponding to the masculine gender of the male teacher + feminine gender of the female schoolgirls) is resolved by (default) masculine gender in Italian. The resulting sentence can only have a partial control $(i \rightarrow i+j)$ reading from the teacher $(i)$ to the teacher $(i)$ and his students 
$(j) .(47 b)$ is a minimal variant: the FQ is tutte ('all.FPL') and reflects the feminine features of the girls alone. The resulting reading is one of proxy control from $i \rightarrow j$, where $j=\operatorname{proxy}(i) .^{24}$

The agreement alternation in (47a) vs. (47b) initially suggests that partial and proxy control can feed FQ $\phi$-agreement. This would only be possible if the controllee in the partial control sentence in (47a) bore syntactic features corresponding to $i+j$, and the controllee in the proxy control sentence in (47b) bore features corresponding to $j=\operatorname{proxy}(i)$. The agreement data thus represents strong evidence for the idea that the $\operatorname{proxy}(i)$ reference on the controllee is syntactically established in a sentence like (47b). Given the discussion in Sect. 4.1, this should only be possible in cases of proxy NOC. Taken together, this entails that the sentence in (47b) must instantiate proxy NOC, not proxy OC. This prediction is confirmed.

Recall that cases of OC should only yield a sloppy reading under ellipsis of the controlled clause since the controlled subject is interpreted as a bound-variable. In contrast, ellipsis of the controlled clause in cases of NOC should allow a strict and sloppy reading. We put this diagnostic to the test in (48). Note that the FQ is marked FPL which forces a proxy control reading:

$\%[\text { [l maestro }]_{i}$ ha chiesto alla receptionist $\left[\mathrm{di} \mathrm{EC}_{\text {proxy }(i)}\right.$ poter the teacher.M.SG has asked to.the receptionist $\mathrm{C}$ may.INF

fare colazione tutt-e proxy $(i)_{\text {insieme e } \quad[\text { il maestro della } 4 \mathrm{~F}]_{k}}$

make.INF breakfast all-F.PL together and the teacher of.the $4 \mathrm{~F}$ uguale.

same

'[The teacher $]_{i}$ asked the receptionist $\left[C P\right.$ (to be allowed) $\mathrm{EC}_{\text {proxy }(i)}$ to have breakfast all proxy (i) $_{\text {together] }}$ and [the teacher of $\left.4 \mathrm{~F}\right]_{k}$ asked the receptionist $\mathrm{ECP}_{C P}$ (to be allowed) $\mathrm{EC}_{\text {proxy }(i), \operatorname{proxy}(k)}$ to have breakfast all proxy $(i), \operatorname{proxy}(k)$ together] too.'

$\checkmark$ SLOPPY: Teacher $1_{i}$ asks permission for Teacher 1's students ${ }_{\text {proxy(i) }}$ to all eat breakfast together and Teacher in $4 \mathrm{~F}_{k}$ asks permission for Teacher in $4 \mathrm{~F}$ 's students $_{\text {proxy }(k)}$ to all eat breakfast together.

$\checkmark$ STRICT: Teacher $1_{i}$ asks permission for Teacher 1's students ${ }_{\text {proxy }(i)}$ to all eat breakfast together and Teacher in $4 \mathrm{~F}_{k}$ asks permission for Teacher 1's students $_{\text {proxy (i) }}$ to all eat breakfast together.

When tested, our Italian consultants concluded that (48) could have both strict and sloppy readings, as described above. This in turn confirms the prediction that (48) (and (47b)) instantiate a case of proxy NOC, not proxy OC. By extension, the proxy controllee may bear features corresponding to $\operatorname{proxy}(i)$ only in cases of NOC.

Strikingly, the same test, when applied to the partial control sentence in (49), forced by the MPL agreement on the FQ, yielded different results:

\footnotetext{
${ }^{24}$ The sentences in (47b), as well as (48), are prefixed by the \%-sign because there is some speaker variation wrt. whether the adjunct that contains the referent of the F.PL FQ should be overt or not. Nevertheless, the variation doesn't pertain to the availability of F.PL agreement under such a reading, which is our primary concern here.
} 
$[\text { Il maestro }]_{i}$ ha chiesto alla receptionist $\left[\mathrm{di} \quad \mathrm{EC}_{i+(j)}\right.$ poter the teacher.M.SG has asked to.the receptionist $\mathrm{C}$ may.INF

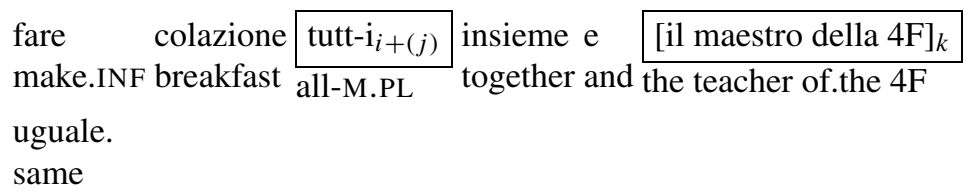

'[The teacher $]_{i}$ asked [the receptionist] $\left[{ }_{C P}\right.$ (to be allowed) $\mathrm{EC}_{i(+j)}$ to have breakfast all $_{i(+j)}$ together] and [the teacher of $\left.4 \mathrm{~F}\right]_{k}$ asked the receptionist ECP (to be allowed) $\mathrm{EC}_{k+(j), * i+(j)}$ to have breakfast all $k(+j), * i+(j)$ together] too.'

$\checkmark$ SLOPPY: Teacher $1_{i}$ asks permission for Teacher $1_{i}+$ Teacher 1 's students $j$ to all eat breakfast together and Teacher in $4 \mathrm{~F}_{k}$ asks permission for Teacher in $4 \mathrm{~F}_{k}$ and Teacher in $4 \mathrm{~F}$ 's students $l$ to all eat breakfast together. $\boldsymbol{X}$ STRICT: Teacher $1_{i}$ asks permission for Teacher $1_{i}+$ Teacher 1 's students ${ }_{j}$ to all eat breakfast together and Teacher in $4 \mathrm{~F}_{k}$ asks permission for Teacher $1_{i}$ and Teacher 1's students ${ }_{j}$ to all eat breakfast together.

For our consultants, the partial control structure (with M.PL FQ) in (49) allowed only sloppy readings under ellipsis, as described in the paraphrases above. The grammaticality judgments in (48) vs. (49) lead to two conclusions. First, a proxy control sentence where the controller has syntactic features corresponding to $i$ and the controllee has syntactic features corresponding to $\operatorname{proxy}(i)$ instantiates a genuine case of NOC. Second, a partial control sentence where the controller has syntactic features corresponding to $i$ and the controllee has syntactic features corresponding to $i+j$ instantiates a genuine case of OC. We take these conclusions to mean that the part-whole $i \rightarrow i+$ reference of the controllee in cases of partial oc can, in principle, be established through a syntactic dependency with the controller. In telling contrast to this, if the proxy controllee bears syntactic features corresponding to $\operatorname{proxy}(i)$, this can only be a case of proxy NOC, where the controllee does not enter into a syntactic dependency with the controller.

\subsubsection{Condition B obviation in German}

Here, we use Condition B obviation effects as a diagnostic for the syntactic features borne by the controllee in a proxy control sentence; i.e. we expect Condition B effects to obtain with a clausemate pronoun that is coreferent with the controller, just in case the referent of the controller is included in that of the controllee. For our German proxy control speakers, a sentence like (50b), which includes such a coreferent pronoun in the controlled clause, was deemed grammatical against the discourse scenario in (50a):

a. Scenario: For an international school trip, the parents are expected to accompany their kids. The parents of one of the students are unable to accompany their child this time. They want their child to still be able to go on the school trip. 


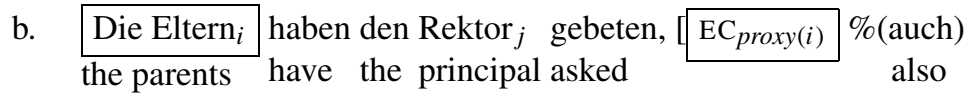

ohne $\mathrm{sie}_{i}$ ins Ausland fahren zu dürfen]. without them in.the abroad travel.INF to may.INF

'The parents asked the principal for permission (for their child) to go abroad without themselves.'

Per the discourse-context in (50a), (50b) is interpreted to mean that the parents $(i)$ ask for permission for their kids $(\operatorname{proxy}(i))$ to go abroad without them $(i)$. If the reference of the controllee were $i$ or $i+$ (due to exhaustive and partial control, respectively), the sentence in (50b) should be ungrammatical (Condition B violation) or nonsensical (stating that an individual is traveling without herself). The fact that our consultants who allowed proxy control deemed this sentence both grammatical and coherent thus indicates that an $i \rightarrow \operatorname{proxy}(i)$ reading is available. This shows that the proxy controllee must bear syntactic features corresponding to $\operatorname{proxy}(i)$, which excludes features associated with $i$, at the stage of the derivation where Condition $\mathrm{B}$ is computed. A Condition B violation is thus obviated in this sentence.

Per the discussion in Sect. 4.1, the proxy controllee may bear syntactic features corresponding to proxy $(i)$ only in cases of proxy NOC. Taken together, this thus predicts that (50b) must instantiate proxy NOC, not proxy OC. This prediction is independently confirmed. We again use the ellipsis diagnostic to tease apart the OC vs. NOC distinction: the latter should allow strict readings under ellipsis of the controlled clause, but the former should not. Just as with the FQ sentences in Italian, German sentences like (50) also substantially facilitate the availability of strict readings (as well as sloppy readings) under ellipsis. This is illustrated in (51):

\begin{tabular}{|l|l|l} 
Die Eltern $_{i}$ & haben die Rektorin \\
$j$ & gebeten, $\left[\mathrm{EC}_{\operatorname{proxy}(i)} \%(\mathrm{auch})\right.$ ohne \\
the parents & also without
\end{tabular} $\operatorname{sie}_{i}$ ins Ausland fahren zu dürfen] und der $\operatorname{Martin}_{k}$ auch. them in.the abroad travel.INF to may.INF and the Martin also

'The parents $s_{i}$ asked the principal ${ }_{j}\left[_{C P}\right.$ to be allowed $\mathrm{EC}_{\text {proxy(i) }}$ to travel abroad without them ${ }_{i}$ ] and Martin $_{k}$ asked [the principal] ${ }_{j}[C P$ (to be allowed) $\mathrm{EC}_{\text {proxy }(i), \text { proxy }(k) \text { to travel abroad without them }} / \mathrm{him}_{k}$ ]too.' (Literal)

$\checkmark$ SLOPPY: The parents $_{i}$ asked the principal $_{j}$ for the parents' children $\operatorname{proxy}(i)$ to be allowed to travel abroad without the parents $i \& \operatorname{Martin}_{k}$ asked the $\operatorname{principal}_{j}$ for Martin's children proxy $(k)_{\text {to }}$ to be allowed to travel abroad without $\operatorname{Martin}_{k}$.

$\checkmark$ STRICT: The parents $_{i}$ asked the principal $_{j}$ for the parents' children proxy $(i)$ to be allowed to travel abroad without the parents $i \& \operatorname{Martin}_{k}$ asked the $\operatorname{principal}_{j}$ for the parents' children proxy $(i)_{\text {to }}$ to be allowed to travel abroad without the parents $s_{i}$.

This data again empirically confirms the idea that the proxy controllee may bear syntactic features associated with proxy $(i)$ only in cases of proxy NOC. 


\subsubsection{Interim summary and the relation to partial control}

Section 4.2 empirically confirmed, via FQ agreement and Condition B obviation effects, the theoretical predictions laid out in Sect. 4.1, namely that when the controllee bears features corresponding to $\operatorname{proxy}(i)$, the proxy control sentence is unambiguously NOC. An interesting point that should be noted here is that, not only our PROXY NOC speakers, but also our PROXY OC speakers, judged the FQ and Condition B proxy control sentences to be cases of NOC. This in turn shows that variation in whether a proxy control sentence is judged OC or NOC does not just hold across speakers; rather, speakers we have classified as PROXY OC must also have an optional NOC parse for proxy control under specific structural conditions. We will explore how to model such intra-speaker variation in Sect. 8.2.

The discussion of FQ-agreement in Sect. 4.2.1 has also exposed an interesting distinction between proxy control and partial control. In contrast to a proxy control sentence with an FQ (cf. Ex. (47b)), which diagnoses a bonafide NOC structure, a partial control sentence + FQ (cf. Ex. (47a)) crucially continues to bear the empirical properties of an OC relation. Specifically, the latter yields only sloppy readings under ellipsis (cf. (49)) while the minimally varying proxy control sentence allows both strict and sloppy elided readings (cf. (48)). Such data indicate that in cases of partial OC, at least in Italian and languages like it, it must be possible to establish the $i \rightarrow i+$ relation between the controller and controllee syntactically (e.g. via Agree or A-movement), which in turn feeds morphosyntactic agreement on the associated FQ. Recent work in Pearson (2016), among others, has argued that partial control is derived semantically (e.g. by referentially extending the denotation of the controllee), and not in the syntax. Taken together with the Italian evidence, this suggests that there may be multiple routes to partial control-a syntactic (or "fake") one, potentially involving exhaustive control by a syntactic controller associated with a comitative PP, and a semantic (or "true") one, involving semantic extension of the reference of the controllee. Such a conclusion has, in fact, been independently argued for in the literature (see for instance Landau 2008; Pitteroff et al. 2017a). The FQ-agreement can, thus, be taken to corroborate these findings.

Our approach to proxy control is simultaneously similar to, and distinct from, this. We have shown, on the one hand, that there are multiple routes to proxy control, just as with partial control. Cases of proxy NOC instantiate "fake proxy" relations: i.e. the $\operatorname{proxy}(i)$ reference on the controllee is established syntactically, albeit not by the controller, but by a logophoric operator, itself denoting proxy $(i)$ at the edge of the controlled CP. In contrast, if genuine cases of proxy OC or "true proxy" do exist (and we will argue in Sect. 5 that they do), the controllee in such cases must get its $\operatorname{proxy}(i)$ reference, not syntactically, but by some other (post-syntactic) mechanism. On the other hand, there are legitimate differences between the cases of partial and proxy control. With partial control, as we have seen, the $i+$ reference on the controllee seems capable of being established in the syntax, already in cases of oc; i.e. cases of partial oc themselves seem to show a bifurcation between purely semantic and syntactic routes to $i \rightarrow i+$. However, in cases of proxy control, this divide, at 
least based on the data presented so far, follows the lines of the OC vs. NOC divide, respectively. ${ }^{25}$

\section{Independent evidence that proxy $\mathrm{OC}$ is genuine}

As we have noted throughout, the discussion in Sect. 4 has only shown that if there are genuine cases of proxy OC, they must syntactically differ from cases of proxy NOC. It has not presented independent evidence that such genuine cases of proxy OC do exist. This is a legitimate concern, given that our proxy OC speakers in German and Italian constitute a clear minority among our consultants. Furthermore, the set of interpretations available to proxy OC is a proper subset of those available for proxy NOC (cf. Ex. (27), so the availability of a proxy OC interpretation alone cannot be taken to conclusively rule out an NOC parse. Finally, as just noted, our PROXY OC speakers in German and Italian could also get an NOC parse for proxy control sentences with a FQ (cf. Ex. (47b)) and coreferent pronoun (cf. Ex. 50b). Taken together, these factors raise the concern that genuine proxy oC might not exist. ${ }^{26}$ If this is indeed the case, it would mean that the superficial effects of proxy OC observed in Sect. 3.2 (obligatory coreference, obligatory de se reading, locality + c-command of controller, and only sloppy readings under ellipsis) are simply the pragmatically restricted readings of a proxy NOC structure. ${ }^{27}$

Below, we present two arguments against this alternative. First, we show that, for our PROXY OC speakers, the availability of an OC parse in a proxy control sentence is independent of the properties of the discourse context. Second, we illustrate that sentences that bear the empirical fingerprint of proxy OC behave systematically differently from their proxy NOC counterparts with respect to syntactically induced perspectival opacity effects. Taken together, this shows, on independent grounds, that genuine proxy OC does indeed exist, and that it involves a distinct syntactic configuration from proxy NOC.

\subsection{Discourse-pragmatic sensitivity: Proxy OC vs. proxy NOC}

If proxy OC were indeed a pragmatically constrained form of NOC, merely mimicking the properties of $\mathrm{OC}$ on the surface, the availability of coreference between the controller and controllee (cf. Sect. 3.2.1), should be directly influenced by properties

\footnotetext{
${ }^{25}$ An anonymous reviewer points out that there may be multiple routes to proxy OC as well, based on their own German judgments that such proxy control is only possible for them in sentences that independently allow a for-PP. The idea would be that this for-PP in the matrix clause can host a DP denoting the proxy individual which can then exhaustively control the PRO in the controlled complement. Such an analysis would then further underscore parallels between "fake" or syntactic partial control and "true" or semantic partial Oc. Nevertheless, we see no clear evidence for this at this stage. If this were the case, we would expect proxy control sentences with FQ and Condition B obviation to be able to have an oc interpretation via the fake proxy route. But this is not attested. We thus leave aside this interesting issue for future work. ${ }^{26}$ We thank an anonymous reviewer for alerting us to this point.

${ }^{27}$ Of course, this line of reasoning renders mysterious why such a putative pragmatic restriction should yield the precise cluster of surface effects that are associated with oc, and none other.
} 
of the discourse context. Concretely, such a reading should be dispreferred in a discourse context that actively favors a non-coreferent interpretation of the controller. Conversely, if proxy OC is, in fact, a grammatical primitive with the syntax and semantics templatically given in (39)/(40), such coreference should obtain obligatorily even in a discourse context that actively disfavors such coreference. We put these predictions to the test in (52):

a. Scenario: Giovanni is a teacher at an all-girls school. He really wants his students to be able to pet the donkey next to the school today, while he himself is at home sick. The principal needs to grant permission to do this. Maria is a helpful colleague of Giovanni's who teaches a different class of students.

b. (Giovanni $i_{i}$ ha detto che) Maria ${ }_{j}$ ha chiesto al preside $_{k}$ [di Giovanni has said that Maria has asked to.the principal C $\mathrm{EC}_{* \operatorname{proxy}(i), \operatorname{proxy}(j)}$ poter accarezzare l' asino vicino a scuola]. may.INF pet.INF the donkey near to school

LITERAL: '(Giovanni $i$ said that) Maria ${ }_{j}$ asked the principal to $\mathrm{EC}_{* \operatorname{proxy}(i), \operatorname{proxy}(j)}$ may pet the donkey near school.'

$\checkmark$ LOCAL CONTROLleR: '(Giovanni ${ }_{i}$ said that) Maria ${ }_{j}$ asked the principal for Maria's students $\operatorname{proxy}(j)_{j}$ to be allowed to pet the donkey near school.'

$\boldsymbol{x}$ Non-Local Controller: '(Giovanni $i{ }_{i}$ said that) Maria ${ }_{j}$ asked the principal for Giovanni's students ${ }_{\text {proxy }(i)}$ to be allowed to pet the donkey near school.'

The discourse context in (52a) makes Giovanni the preferred choice of proxycontroller since it makes clear that he has, indeed, been meaning to ask the principal for permission for his students to pet the donkey. To make such a choice even more salient, Giovanni is also overtly represented as the matrix, non-local subject of (52b). Under the view that (52b) has only an NOC parse, we fully expect that discourse salience should at least allow Giovanni to be a controller. However, for our PROXY OC consultants in Italian, coreference with a local controller, Maria, is obligatory, even under these circumstances. We take this to indicate that obligatory coreference between the controller and controllee, for such speakers, is not due to pragmatic conditioning.

To drive this point home, we now add a FQ associated with the proxy controllee in (52b). We have stated that the addition of a FQ (whose agreement clearly reflects the exclusion of the referent of the controller in that of the controllee) forces an NOC parse. As such, we expect that such a sentence should now suddenly allow not just Maria but also Giovanni as a proxy controller, with the latter actually being the preferred choice, given the discourse context. This prediction is met. (53b) which has the FQ tutte ('all') bears 3FPL features which reflects the proxy features of the controllee: 
a. Scenario: $c f .(52 a)$.

b. (Giovanni $i_{i}$ ha detto che) Maria ${ }_{j}$ ha chiesto al preside $_{k}$ [di Giovanni has said that Maria has asked to.the principal C $\mathrm{EC}_{\text {proxy }(i), \operatorname{proxy}(j)}$ poter accarezzare l' asino vicino a scuola may.INF pet.INF the donkey near to school

tutt-e insieme].

all-F.PL together

LITERAL: '(Giovanni $i_{i}$ said that) Maria ${ }_{j}$ asked the principal to $\mathrm{EC}_{\text {proxy }(i), p r o x y(j)}$ may pet the donkey near school all $\operatorname{proxy}(i), \operatorname{proxy}(j)$ together.'

$\checkmark$ LOCAL CONTROLLER: '(Giovanni $i_{i}$ said that) Maria ${ }_{j}$ asked the principal for Maria's students $\operatorname{proxy}_{(j)}$ to be allowed to pet the donkey near school all together.'

$\checkmark$ Non-Local Controller (preferred): '(Giovanni ${ }_{i}$ said that) Maria $_{j}$ asked the principal for Giovanni's students proxy $(i)$ to be allowed to pet the donkey near school all together.'

We take this as compelling initial evidence that the requirement of a local controller for our PROXY OC speakers is not due to pragmatic conditioning but stems from independent reasons having to do with the syntax and semantics of such sentences. We additionally conclude that our PROXY OC speakers have an additional NOC parse that is forced by the addition of a FQ, as in (53).

\subsection{Perspectival opacity: Proxy OC vs. proxy NOC}

We now show that proxy OC in Italian does not bear the (mental and spatial) perspectival interpretation that is associated with cases of NOC (Kuno 1975; Landau 2013, and many others). But such an interpretation is shown to be independently available in unambiguously NOC proxy sentences, diagnosed by the presence of an embedded subject FQ. Following prior work (Landau 2013; McFadden and Sundaresan 2018, a.o.), we take this to be indicative of a syntactic distinction between proxy OC and proxy NOC.

Consider the examples in (54) below, involving a predicate of personal taste gustosissime ('super tasty'), which reflects the subjective opinion/mental perspective of some salient individual (Lasersohn 2005; Stephenson 2007, a.o.). For our PROXY OC consultants, the choice of perspective-holder for the taste-predicate in a given sentence varies according to whether that sentence is independently interpreted as proxy OC or proxy NOC (diagnosed by the presence/absence of a FQ):

Predicate of personal taste-mental perspective:

a. Scenario: The teacher of an all-girls school wants to reward his students with a bag of (fried) chips, which he knows the students love. But his students are training for an athletic competition and have to watch their diet, and so the teacher first makes sure their coach approves of this. 
b. Il maestro $_{i}$ ha chiesto all' allenatore ${ }_{j}\left[\mathrm{di} \mathrm{EC}_{\text {proxy }(i)}\right.$
the teacher has asked to.the coach
may.INF

mangiare quelle gustosissime speaker $(k), i, * \operatorname{proxy}(i)_{\text {patatine]. }}$

eat.INF those super.tasty chips

LITERAL: The teacher ${ }_{i}$ asked the coach $_{j}$ to $\mathrm{EC}_{\text {proxy }}(i)$ may eat those super tasty chips.'

$\approx$ The teacher $_{i}$ asked the coach $_{j}$ for the teacher's students allowed to eat the chips that are super-tasty according to ....

i. $\checkmark$ the speaker $_{k}$

ii. $\checkmark$ the teacher $i$

iii. $X$ the teacher's students proxy $(i)$.

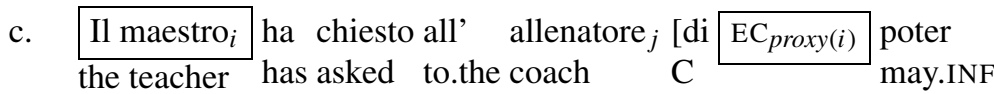

\begin{tabular}{lll|}
\hline tutt-e $\mathrm{e}_{\text {proxy }(i)}$ & mangiare quelle & gustosissime \#speaker $(k), \# i, \operatorname{proxy}(i)$ \\
all-F.PL & eat.INF those & super.tasty
\end{tabular}

patatine ].

chips

LIT: 'The teacher $i$ asked the $\operatorname{coach}_{j}$ to $\mathrm{EC}_{\text {proxy }(i)}$ may all proxy(i) $_{(i)}$ eat those super tasty chips.'

$\approx$ 'The teacher ${ }_{i}$ asked the coach for all the teacher's students $_{\text {proxy }(i)}$ to be allowed to eat the chips that are super-tasty according to ....
i. \#the speaker ${ }_{k}$
ii. \#the teacher $i$
iii. $\checkmark$ the teacher's students proxy(i) .

The salient candidates for perspective-holder for gustosissime ('super tasty') in the sentences above are: the students $(\operatorname{proxy}(i))$, the teacher $(i)$ and the speaker of the utterance $(k)$. In (54b), which lacks a FQ, it is either the utterance-speaker (preferred) or the teacher who finds the fried chips super tasty, but crucially not the teacher's students. But in (54c), which minimally differs from (54b) by having a FQ, the taste predicate denotes the perspective of the teacher's students: the perspectives of the speaker and teacher are clearly dispreferred. We have seen that the presence of an FQ forces a proxy NOC interpretation. The data above thus shows, in essence, that the proxy controllee may be a mental perspective-holder just in case the proxy control sentence instantiates a dedicated NOC underlying structure.

Analogous results obtain with proxy structures like (55), which deploys the spatial adverb sinistra ('left') to track spatial perspective: 
(55) Spatial adverb-spatial perspective:

a. Scenario: There are three donkeys next to the school. They are standing in a line. The students are standing in a line facing the donkeys; their teacher is standing next to the donkeys and facing the students. The students are petting one of the donkeys. You know that they are not allowed to do this without the farmer's permission so you are getting a bit nervous. Gianni, who is also present on the scene, reassures you by saying:

b. Tutto a posto. La maestra ${ }_{i}$ aveva chiesto al contadino $j$ [di all $\mathrm{OK}$ the teacher had asked to.the farmer $\mathrm{C}$ $\mathrm{EC}_{\text {proxy }(i)}$ poter=lo accarezzare, almeno quello sulla may.INF $=$ it pet.INF at.least that.one on.the

sinistra $_{\text {speaker }(k), i, * \operatorname{proxy}(i)}$.
left

LIT: 'It's fine. The teacher ${ }_{i}$ asked the farmer ${ }_{j}$ to $\mathrm{EC}_{\text {proxy(i) }}$ may pet at least the one on the left.'

$\approx$ It's fine. The teacher ${ }_{i}$ asked the farmer ${ }_{j}$ for the teacher's students $_{\text {proxy }(i)}$ to be allowed to pet at least the one on the left ....

i. $\checkmark$ of the speaker $_{k}$ (Gianni)

ii. $\checkmark$ of the teacher $i$

iii. $\boldsymbol{X}$ of the teacher's students proxy $(i)$

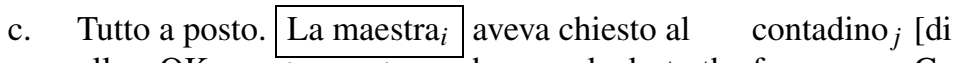
all $\mathrm{OK}$ the teacher has asked to.the farmer $\mathrm{C}$

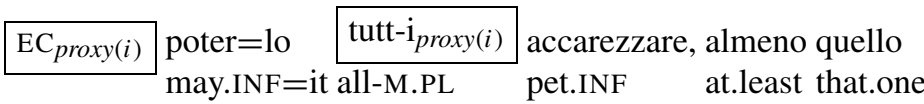

sulla sinistra\#speaker $(k), \# i, \operatorname{proxy}(i)$.

on.the left

LIT: 'It's fine. The teacher ${ }_{i}$ asked the farmer ${ }_{j}$ to $\mathrm{EC}_{\text {proxy }(i)}$ may all pet at least the one on the left $t_{\text {speaker }}(c)$,\#i,proxy $(i)$.' (Literal)

$\approx$ 'It's fine. The teacher ${ }_{i}$ asked the farmer ${ }_{j}$ for all proxy $(i)_{\text {i }}$ the teacher's students $_{\text {proxy }(i)}$ to be allowed to pet at least the one on the left ....

i. \#of the speaker ${ }_{k}$ (Gianni)

ii. \#of the teacher $r_{i}$

iii. $\checkmark$ of the teacher's students proxy $(i)$

In (55b), as in (54b), there is no FQ: the leftness of the donkey is interpreted from either the spatial perspective of the speaker or that of the teacher. Crucially, again, the perspective of the proxy controllee, namely the teacher's students, is unavailable. But once we add the FQ to this sentence (55c), which now diagnoses an unambiguously NOC proxy control sentence, the perspective of sinistra ('left')necessarily shifts to that of the proxy controllee, namely the teacher's students.

Under an analysis where all proxy control underlyingly involved NOC, with the OC vs. NOC distinction being merely pragmatically conditioned and superficial, such 
a perspectival shift between the minimal pairs with and without a FQ would be mysterious. But this systematic alternation is immediately accounted for under the assumption (cf. Ex. (41)) that the FQ sentences independently diagnose an NOC parse where the controlled complement hosts a logophoric operator as in Ex. (56) (based on McFadden and Sundaresan 2018):

Logophoric NOC: Perspective Sensitive Items (PSIs):

[ [ PerspP PerspHolder Persp ${ }^{0}\left[\ldots\left[\mathrm{EC}_{\text {proxy }} \ldots\right.\right.$...PSI ... ] ] ]

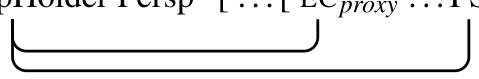

This logophoric pronoun binds the EC (yielding proxy NOC) as well as the perspectival variable associated with the PSI (e.g. taste-predicate or spatial adverb) in its scope. The root clause hosts its own perspectival operator which refers to available salient individuals like the speaker and the referent of the controller. This operator is disbarred from binding the PSI because the perspectival operator in the controlled complement is minimally closer. As such, the PSI only reflects the perspective of the (proxy) controllee in bonafide cases of proxy NOC. ${ }^{28}$

In contrast, proxy control sentences without an FQ must diagnose a distinct controlled complement which lacks the structure to host an embedded logophoric operator (as mentioned before, if the logophoric operator were syntactically present in such structures, it would necessarily bind, being minimally closer). The binding of the EC in such cases must thus be handled separately, via a syntactic relationship with the controller, as discussed in Sects. 4.1 and 4.2. The PSI in such structures is bound by a root logophoric operator in such cases. Since the most salient perspective-holders at this stage in the derivation are the utterance-speaker and the attitude-holder of the embedded proposition (i.e. the proxy controller), the PSI denotes the mental/spatial perspective of one of these individuals:

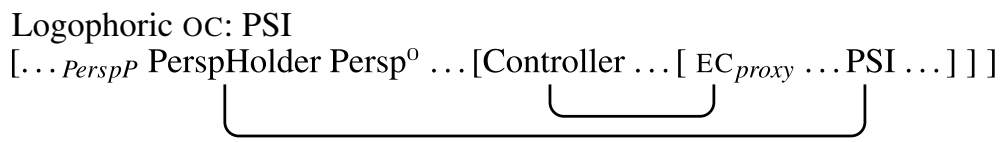

We take such evidence to show the following. When the syntactic features associated with the proxy controllee is $\operatorname{proxy}(i)$ (as diagnosed by the presence of a FQ with matching features) the proxy control sentence is umabiguously parsed as NOC (even by PROXY OC speakers) with a dedicated underlying structure. But when the proxy control sentence appears without such a FQ, our PROXY OC speakers unambiguously parse the sentence as proxy OC, with a distinct underlying structure from cases of proxy NOC. Going forward, we thus take it to be conclusive that proxy control comes in two underlyingly distinct forms: OC and NOC. For PROXY OC speakers, both an OC and NOC parse are, in theory, available under a proxy control predicate. But the NOC parse is forced only when proxy OC is made independently unavailable.

${ }^{28}$ The perspectival pronoun, being a regular pronoun, deictically denotes the teacher's students, which are salient in the discourse context and satisfy conditions of perspective-holding (see Sundaresan 2012, 2018, a.o. for more). 


\section{Insights into the role of permission modality}

Consider again our definition of proxy control (repeated from (23):

Generalized proxy control (OC and NOC) relation:

a. For any two sets of individuals $i$ and $j$, where $i$ is a core participant in a permission-seeking or -granting speech-event $e_{1}$ and $j$ is a core participant in $e_{2}$, an eventuality that is consistent with permission being granted in $e_{1}, j=\operatorname{proxy}(i)$ iff:

(i) in $e_{1}, i$ acts on behalf of $j$;

(ii) in $e_{2}, j$ stands in for $i$;

(iii) $i$ and $j$ are directly associated through some discourse-salient group or activity.

b. In cases of proxy control, if a controller denotes $i$ and the controllee denotes $j, j=\operatorname{proxy}(i)$.

Here, we offer some preliminary thoughts on the nature of the connection between proxy control and permission modality.

\subsection{The special nature of a proxy control predicate}

We have seen that proxy control, in both German and Italian, is restricted to speechpredicates of permission-seeking (e.g. 'ask') or -granting (e.g. 'promise'). But why should this be the case? What, in other words, prevents a proxy control reading under a different kind of control predicate, e.g. a bouletic control predicate like 'want' or 'hope'?

We tentatively propose that this restriction goes to the heart of what a proxy relation is. Per the definition in (58), the proxy control predicate must describe an event where one set of individuals acts on behalf of another. Interestingly, this condition seems to immediately exclude many control predicates from consideration. The modality associated with a control predicate like 'want' is internal to (and thus inseparable from) the wanter: i.e. if I want $p, p$ must represent my own desire. As such, in the exhaustive control sentence in (59), I want it to be the case that I eat pizza tomorrow. In the partial control sentence in (60), I want it to be the case that I and a discourse-salient set of individuals meet at 5pm tomorrow. In (61), I want it to be the case that John eats pizza tomorrow.

$$
\begin{aligned}
& \mathrm{I}_{i} \text { want }\left[\mathrm{EC}_{i}\right. \text { to eat pizza tomorrow]. } \\
& \mathrm{I}_{i} \text { want }\left[\mathrm{EC}_{i+} \text { to meet at } 5 \mathrm{pm}\right. \text { tomorrow]. } \\
& \mathrm{I}_{i} \text { want }\left[\mathrm{John}_{j}\right. \text { to eat pizza tomorrow]. }
\end{aligned}
$$

Regardless of whether my wanting is about myself (Ex. (59)), myself and others (Ex. 60), or about someone else entirely (Ex. 61) — the bouletic alternatives encoded in the non-finite complement are mine, not anyone else's. Of course, I can say something like (62):

(62) On behalf of my son, I want this to be a successful event. 
But (62) still expresses my internal desire based on my belief (which may or may not be correct) that this is what my son would want. Ultimately, short of me actually possessing my son's mind in some sort of fantastic scenario, I cannot literally feel my son's thoughts, hopes and desires. I can, at best, only empathize with them.

In contrast, in certain configurations, I can ask someone for something on behalf of a third set of individuals; similarly, I can, in certain cases, communicate a promise to someone via an intermediary (my immediate addressee). This special property might, in turn, have to do with predicates like 'ask' and 'promise' having a more complex modal profile in their (non-default) subject and object control readings, respectively. This distinction is illustrated for the default and control-shifted readings of 'ask' below:

$$
\begin{aligned}
& \operatorname{Mary}_{i} \operatorname{asked~me~}_{j} \text { [EC }_{j} \text { to leave early]. } \\
& \text { Mary }_{i} \text { asked me } \\
& \text { (for permission) [EC } i \text { to leave early]. }
\end{aligned}
$$

Both (63) and (64) involve Mary asking me for something. Under the object control reading in (63), what Mary asks of me is that I leave early. More formally (and simplifying somewhat), (63) states that I leave early in all possible worlds which are compatible with what Mary asks me in the actual world. Under the subject control reading in (64) what Mary asks me is that I cause a state of affairs where Mary is permitted to leave early. This reading is more complex: in addition to expressing an illocutionary request to me by Mary, it also involves a semantics of permission which is the content of Mary's request. This complex modality can, of course, be discerned on the surface in the control-shifted reading (which is crucially absent in the unshifted one). As we have already noted in Sect. 2.1, proxy control sentences in German and Italian often involve an overt permission modal (e.g. German dürfen and Italian poter, both meaning 'may') which lies under the scope of the (also overt) illocutionary control predicate.

In both (63) and (64), the illocutionary modality of Mary's asking is again internal to Mary herself: short of Mary possessing someone else's voice box, she can't express anyone else's request but her own. In this sense, we see a parallel with the 'want' cases above. However, the permission that Mary is asking for in (64) may be externalized: i.e. Mary may ask permission for herself or for someone else. This immediately explains why proxy control is possible under 'ask' only under the modally more complex subject control reading in (64), but not under the modally simpler (pure illocutionary) default object control reading in (63). The same kind of argument can be extended to control-shifted vs. unshifted variants of 'promise': only the former embeds permission modality. By this same measure, we have a handle on why proxy control is not possible under predicates like 'want' or 'hope': these too express only a simple modality which carves out possible worlds of desire and hope which are strictly internal to the wanter and hoper. Interestingly, there are reflexes of this modal contrast elsewhere in language. For instance, English has a term "spokesperson" which precisely denotes an individual who speaks on behalf of another; but there are no corresponding terms like "want-person" or "hope-person" because these don't correspond to concepts that are plausibly expressible in the actual world. Additional reflexes of this distinction might be found in the realm of evidential marking. I cannot have direct evidence of someone's hopes and wants since I cannot witness 
someone's feelings: at best, such evidence must be indirect. However, I can directly witness someone saying or asking something, e.g. by virtue of being present when the utterance is made. ${ }^{29}$

\subsection{Non-finite clauses cannot be epistemic}

We now ask why proxy control predicates encode deontic modality (as opposed to some other kind of modality). The answer to this appears to have to do with independent syntactic and semantic restrictions placed on the modality of non-finite clauses.

Bhatt (2006) shows that the covert modality of interrogative clauses is systematically conditioned by their finiteness, as illustrated in (65) vs. (66):

wh-FINITE QUESTION: (Bhatt 2006, Ex. (213b), 119)

John knows when he must have been at home.

? Deontic: It is necessary for the satisfaction of some goal/by some law for John to have been at home at time $x$. John knows this.

$\checkmark$ Epistemic: John is an amnesiac. It follows from the evidence that he was at home at time $x$. John knows this.

wh-NON-FINITE QUESTION: (Bhatt 2006, Ex. (214a), 120)

John knows when to have been at home. ${ }^{30}$

$\checkmark$ Deontic: $\exists t$ John knows that having been home at time $t$ satisfies some goal/some law.

$\boldsymbol{x}$ Epistemic, $\boldsymbol{x}$ Circumstantial

Based on such differences, Bhatt concludes that "The modality in an infinitival question is, for the most part, deontic/bouletic i.e. in consonance with certain laws, conventions, or desires." (Bhatt 2006, 117). Crucially in addition, Bhatt independently shows that infinitival questions always involve modality, with the source of such modality being the interrogative complementizer.

Strikingly, this pattern is replicated with 'ask'-the predicate that has been involved in a majority of our proxy control examples (both in German and Italian) in this paper. The complement of 'ask' can, in principle, carry either epistemic or deontic modality, depending on whether 'ask' is a request for information or permission. But non-finite complements of 'ask' seem to be restricted to a deontic interpretation, as shown below:

FINITE CP UNDER 'ask':

Maria asked whether she could have smoked inside.

$\checkmark$ Deontic/Bouletic: It is necessary for the satisfaction of some goal/by some law for Maria to have smoked inside. Maria asks about this.

\footnotetext{
${ }^{29}$ Thanks to Peggy Speas (p.c.) for pointing out this correlation.

${ }^{30} \mathrm{An}$ anonymous reviewer notes that they find this example ungrammatical. But for many English speakers we consulted, and for the native English-speaking author, this sentence is grammatical, so we have left it in.
} 
$\checkmark$ Epistemic: Maria is an amnesiac. It follows from the evidence that there is a possibility of her having smoked inside. Maria asks about this.

NON-FInITE CP UNDER 'ask':

Maria asked to smoke inside.

$\checkmark$ Deontic: It is necessary for the satisfaction of some goal/by some law for Maria to smoke inside. Maria asks about this.

\section{$\boldsymbol{x}$ Epistemic, $\boldsymbol{x}$ Circumstantial}

Consider the sentence in (69), repeated from (34):

$$
\begin{aligned}
& \mathrm{Maria}_{i} \text { hat } \operatorname{Susan}_{j} \text { gebeten [PROproxy(i) früher gehen zu dürfen]. } \\
& \text { Maria has Susan asked earlier go.INF to may.INF } \\
& \text { 'Maria }{ }_{i} \text { asked } \operatorname{Susan}_{j}\left[\mathrm{PRO}_{\text {proxy(i) }}\right. \text { to be allowed to leave early].' }
\end{aligned}
$$

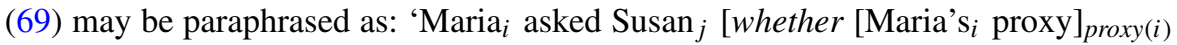
may leave early].' This suggests that the control complement of 'ask' also involves a question infinitival headed by an interrogative complementizer. The difference is that this complementizer is silent, and not overt. The complement of 'ask' in control constructions is definitionally non-finite, yielding the result that all control under 'ask'-class predicates must necessarily be deontic, in line with Bhatt's observations.

Anand and Hacquard (2013) extend Bhatt's conclusion to finite and non-finite intensional complements, more generally. They show that, while the finite complement of an attitude verb like penser ('think') in French may have an epistemic interpretation (Ex. (70)), its non-finite counterpart may only be interpreted deontically (Ex. (71)), (adapted from Anand and Hacquard 2013, Exx. (70)-(71), 39):

FINITE INTENSIONAL COMPLEMENT:

Marie pense qu'elle doit être enceinte.

Marie thinks that she must be pregnant.

$\checkmark$ Deontic, $\checkmark$ Epistemic: 'Marie thinks she must be pregnant.'

(71) NON-FINITE INTENSIONAL COMPLEMENT:

Marie pense devoir être enceinte.

Marie thinks must-INF be pregnant

$\checkmark$ Deontic, $\boldsymbol{X}$ Epistemic: 'Marie thinks she must be pregnant.'

Following Cinque (1999), they propose that the contrast in (70)-(71) might have a structural basis: i.e. "infinitives [might be] structurally too small to contain the structural position of epistemics." (Anand and Hacquard 2013, 39). Independent evidence in the literature robustly shows that epistemic modality is hosted higher than deontic modality (Iatridou 1990; Abusch 1997; Cinque 1999; Hacquard 2006, among others). Taken together, these then explain why non-finites can host deontic modality, but cannot host epistemic modality. 
Anand and Hacquard's proposal allows us to explain the necessary presence of deontic modality under non-interrogative predicates that are compatible with permission-granting, such as 'promise.' : ${ }^{31}$

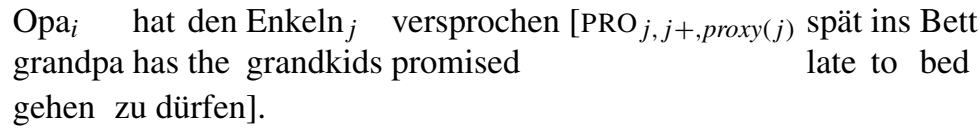

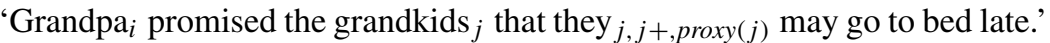

Intuitively, the only difference between 'promise' and 'ask' (in their control-shifted readings, which are the only ones relevant for proxy control) is that the latter involves an illocution of permission-seeking while the former involves one of permissiongranting. But in both cases, the controllee denotes the individual to whom permission is granted. We can capture this under the idea that the illocutionary difference between (the shifted variants of) 'ask' and 'promise' comes from the verbs themselves while the associated permission modality on the non-finite complementizer in their scope remains identical. The difference between the two predicates lies only in their rogativity. The complementizer under (shifted) 'ask' is rogative (or $[+w h]$ in terms of Bhatt 2006), as mentioned above, while that under (shifted) 'promise' is declarative (or $[-w h]$, per Bhatt) with a future-oriented temporal modality.

\section{Proposal: Modeling proxy OC vs. proxy NOC}

We now turn to an analysis of the properties of proxy control (OC and NOC) summarized in (73) below:

Properties of proxy OC and NOC:

a. Proxy control comes in two varieties: OC and NOC, which have distinct syntactic and semantic properties.

b. In cases of proxy oc:

(i) There is a syntactic dependency between the controller and controllee.

(ii) Direct consequence: the proxy controllee cannot bear syntactic features corresponding to $\operatorname{proxy}(i)$, for a controller bearing features corresponding to $i$.

c. In cases of proxy NOC:

(i) There is no syntactic relationship between the controller and controllee: the controllee is syntactically dependent on a clauseinternal pronominal operator which, in turn, discourse-pragmatically refers to the controller.

\footnotetext{
${ }^{31}$ In German sentences like (72) below, the permission semantics is further enforced by the modal dürfen ('may'), as we have repeatedly noted. The Italian variants of such sentences often also involve a modal, namely poter ('may').
} 
(ii) Direct consequence: the proxy controllee can bear syntactic features corresponding to $\operatorname{proxy}(i)$, for a controller bearing features corresponding to $i$; Empirical evidence from FQs and Condition $\mathrm{B}$ obviation effects shows that it indeed does do so.

d. Both proxy OC and proxy NOC sentences involve a complex modality which combines the illocutionary modality of the control predicate with a permission modality introduced in the scope of this predicate.

\subsection{Modeling proxy oC}

\subsubsection{Life-cycle of proxy $\mathrm{OC}$}

In Sect. 4.1, we saw that variants of oc that are more restricted with respect to reference, tense and mood of the controlled clause involve a direct syntactic dependency between the controller and controllee (cf. Ex. (39)). Less restricted cases of oc, where the controlled clause may host its own tense, mood and reference (e.g. allowing nonexhaustive control and non-anaphoric tense) involve a syntactic dependency between the controller and controllee which is mediated by the phasal $\mathrm{C}$ head of the controlled clause (cf. Ex. (40)).

Given that proxy OC must involve permission modality in the scope of the control predicate and instantiates a different kind of non-exhaustive control, we propose that it conforms to the template of mediated OC, with the controller-controllee syntactic dependency proceeding via the complementizer that heads the controlled CP. We have further observed that proxy control sentences involve a complex illocutionary + permission modality. To capture this, we propose that proxy control sentences (e.g. under a subject control variant of 'ask' or object control variant of 'promise') actually involve two nested levels of control. The sentence in (74) thus corresponds to the structure in (75), and is in theory compatible with exhaustive, partial, and proxy OC readings:

$$
\begin{aligned}
& \text { Marie hat mich gebeten [[EC früher gehen] EC zu dürfen]. } \\
& \text { Marie has me asked earlier go.INF to may.INF } \\
& \text { LITERAL: 'Marie asked me [EC to may [EC leave early]].' } \\
& \text { Marie }_{i} \text { asked me }{ }_{j}\left[{ }_{C P_{1}} C_{[+w h]} \text { EC to (may) }{ }_{\left[\mathrm{CP}_{2}\right.} C_{\text {permission }}\right. \text { EC to leave } \\
& \text { early]]. }
\end{aligned}
$$

The innermost control clause, $\mathrm{CP}_{2}$, is headed by a complementizer which introduces permission modality: we provisionally label this as $C_{\text {permission }}$ above. In (74)-(75), we assume that the overt permission modal dürfen (and poter in Italian) selects the $\mathrm{CP}$ headed by $C_{\text {permission }}$. This means that dürfen and poter do not themselves realize permission modality: they select it. ${ }^{32}$

The $C_{\text {permission }}$ head mediates the syntactic dependency between the innermost controllee and the intermediate controllee of the next higher clause in $\mathrm{CP}_{1}$. Structurally, $C_{\text {permission }}$ must also be the head of the $\mathrm{CP}_{2}$ phase: as such, it can serve as an

\footnotetext{
${ }^{32}$ An alternative is that these overt modals directly realize $C_{\text {permission }}$. This should make no significant difference to our analysis, so we remain agnostic on this point.
} 
escape hatch for syntactic dependencies across $\mathrm{CP}_{2}$ (Chomsky 2001, et seq.). Turning now to the medial clause $\mathrm{CP}_{1}$, we propose that this is headed by a complementizer which is specified as [+wh] and encodes the illocutionary rogativity associated with the control predicate 'ask'. This $\mathrm{C}$ head also mediates the control dependency: this time between the intermediate controllee and the matrix controller. Additional evidence that this is also an instance of a mediated syntactic dependency comes from object control readings under 'ask' (which, as we have noted, does not embed permission modality) - but still allows non-anaphoric tense, and non-exhaustive control (e.g. "Marie $i$ asked $\operatorname{Susan}_{j}$ [EC $j+$ to meet at 5pm]"). This, in turn, means that this rogative $\mathrm{C}$ also heads a phase corresponding to $\mathrm{CP}_{1}$.

How is the proxy $i \rightarrow \operatorname{proxy}(i)$ relation established in such a structure? The empirical and theoretical discussion so far has determined that the controllee in proxy OC constructions cannot bear syntactic features corresponding to $\operatorname{proxy}(i)$. At the same time, we have seen that the syntax must play a central role, in such cases, in establishing a (mediated) link between the controller and controllee. We reconcile these two notions by proposing that proxy OC involves a hybrid cross-modular grammatical relation. In the syntax, the controller and controllee enter into a syntactic relationship (mediated by both the innermost $C_{\text {permission }}$ and medial illocutionary C). Such a relation is compatible with both A-movement- and Agree-based approaches to OC. For reasons of concreteness, we will adopt the latter. We assume that both the medial and innermost controllee probe upward (see again McFadden and Sundaresan 2018; Fischer 2018, for upward Agree-based treatments of oC) to get some unvalued feature $[F: \ldots]$ valued against a matching valued feature $[F: \underline{\mathrm{val}}]$ with the controller, mediated by the respective $\mathrm{C}$ heads. Going forward, we will also represent the controllee in cases of OC as PRO following the convention in Agree-based theories of control. This mediated Agree operation simply copies the features of the controller onto each of the controllees, yielding an $i \rightarrow i$ relation as the input to the post-syntactic interpretation at LF, as shown in (76b). We propose that the reference of the controllee is subsequently semantically extended from $i \rightarrow \operatorname{proxy}(i)$, as depicted in (76c). Taken together, this yields the superficial $i \rightarrow \operatorname{proxy}(i)$ proxy oc relation between the controller and controllees, which has been constrained by the structural parameters for OC. The life-cycle of proxy OC is schematically illustrated below: ${ }^{33}$

\section{Proxy OC: syntactic life-cycle:}

a. [Marie $i$ asked [ $C_{[+w h]} \mathrm{PRO}_{i}$ to [ $C_{\text {permission }} \mathrm{PRO}_{i}$ leave early] ].

b. $\quad\left[\mathrm{DP} V\left[\mathrm{C}_{[+w h]}\right.\right.$ PRO ... [ $\left[\mathrm{C}_{\text {permission }}\right.$ PRO ...]]]

c. Semantic extension: $i \rightarrow \operatorname{proxy}(i)$

Final Output: Marie ${ }_{i}$ asked [ $C_{+w h} \mathrm{PRO}_{i}$ [ $C_{\text {permission }} \mathrm{PRO}_{\text {proxy(i) }}$ to leave early]]

\footnotetext{
${ }^{33}$ In Sect. 7.1.2, we present empirical evidence to show that this extension only applies to the innermost $\mathrm{CP}$ headed by $C_{\text {permission. }}$. This is represented accordingly in (76c) below.
} 


\subsubsection{The notion of semantic extension}

The idea of semantic extension builds on prior insights in Pearson (2016) for cases of partial OC. A control sentence like (77) might be paraphrased as a first-person attitude on the part of the controller:

$$
\begin{aligned}
& \text { Marie }_{i} \text { expected [PRO } \\
& \approx \text { Marie }_{i} \text { expected, "I will leave early]. }
\end{aligned}
$$

In other words, the control complement, denoting the content of the attitude, is interpreted obligatorily de se. The conventional way to capture this (following pioneering work in Lewis 1979; Chierchia 1989) is to have the control complement denote a selfascribed property on the part of the controller. Self-ascribed properties, in contrast to propositions, are formally represented as functions from world-individual pairs, also called centered worlds, to truth-values. The individual variable in the centered world stands for the attitude-holder's candidate for herself (i.e. who the attitude holder considers to be herself) in the corresponding world. The control predicate quantifies over the centered worlds, restricting them to all and only those world-individual pairs which are compatible with the meaning of the control predicate. Thus, (77) states that, in every centered world $\left\langle w^{\prime}, x\right\rangle$ that is compatible with Marie's expectations in the current world, $x$ will leave early in $w^{\prime}$. The controlled PRO subject is nothing other than the quantified-over individual variable $x$, representing Maria's candidate for herself in a given world.

Pearson builds on this background to propose a semantics of partial control for a sentence like (78):

Marie $_{i}$ expected [PRO $i+$ to meet tomorrow].

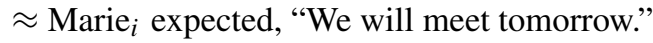

Unlike (77), the controlled PRO in (78) denotes a set of individuals that properly includes Marie; i.e. Marie expects, not that she will meet tomorrow, but that a group of individuals that includes her will meet tomorrow. Pearson proposes that 'expect' must still quantify over all the centered worlds which are compatible with Marie's expectation in the current world, as before. However, the truth of the property expressed by the control complement is determined, not directly with respect to these centered worlds, but relative to extensions of these centered worlds which capture the part-whole relation. In other words, for each of the centered worlds $\left\langle w^{\prime}, x\right\rangle$ that is quantified over, there must be some corresponding individual $y$ which includes $x$ such that the property of meeting tomorrow is true of $y$ (rather than of $x$ ) in $w^{\prime}$. Thus, (78) yields the desired reading that, in every centered world that is compatible with Marie's expectations in the current world, the set of individuals that includes Marie's candidate for herself in a given world will meet at $5 \mathrm{pm}$ in that world. This extension applies post-syntactically, at LF, by a dedicated 'part of' relation, defined for time-intervals and individuals, as in (79):

(79) 'Let the part of relation ' $\leqslant$ ' be defined over both sets and plural individuals, the latter being objects constructed via the sum formation operator ' + '. Hence: 
a. For any two sets $P$ and $Q, P \leqslant Q$ iff $P \subseteq Q .^{34}$

b. For any two individuals $a$ and $b, a \leqslant b$ iff $a+b=b$." (Pearson 2016, Ex. (27):702)

Consider now the German or Italian equivalent of the proxy OC relation below:

Marie $_{i}$ asked Susan $_{j}$ [to (may) [PRO proxy(i) leave early].

$\approx$ Marie asked Susan: "May the set of individuals related to me leave early?"

The control complement of (80) is also interpreted obligatorily de se (cf. Sect. 3.2.4), expressing Marie's awareness that the group of individuals she is asking permission for is related to herself and not someone else. This suggests that the property view of modal quantification must also apply to cases of proxy OC. As we have noted, proxy control predicates are illocutionary predicates which embed an additional modality of permission-seeking or -granting. A speech-event involves, not one, but two arguments corresponding to the speaker and the addressee: as such intensional quantification under such a verb must be over doubly-centered worlds, or world-individual triples. A second layer of modality is contributed by the permission modal ('may'): we assume that this quantifies over centered worlds which pair the individual who is permitted to do something with a specific world. In a sentence like (80), these would be defined as in (81) and (82): ${ }^{35}$

$\operatorname{ASK}_{x, y, w}=\left\{\left\langle x^{\prime}, y^{\prime}, w^{\prime}\right\rangle: w^{\prime}\right.$, with $x^{\prime}$ as the counterpart in $w^{\prime}$ of $x$ and $y^{\prime}$ as the counterpart in $w^{\prime}$ of $y$, is compatible with what $x$ asks of $y$ in $\left.w\right\}$

$\operatorname{PERMISSION}_{x, w}=\left\{\left\langle x^{\prime}, w^{\prime}\right\rangle: w^{\prime}\right.$, with $x^{\prime}$ as the counterpart in $w^{\prime}$ of $x$, is compatible with what $x$ is permitted in $w$ \}

To get the desired proxy control reading in a sentence like (80), we have proposed, building on Pearson (2016), that proxy OC is also derived via semantic extension. The difference is that, in cases of proxy OC, such an extension involves a proxy relation, defined as in (83), rather than a part-of relation:

\section{Generalized proxy relation:}

For any two sets of individuals $i$ and $j$, where $i$ is a core participant in a permission-seeking or -granting speech-event $e_{1}$ and $j$ is a core participant in $e_{2}$, an eventuality that is consistent with permission being granted in $e_{1}, j$ $=\operatorname{proxy}(i)$ iff:

(i) in $e_{1}, i$ acts on behalf of $j$;

(ii) in $e_{2}, j$ stands in for $i$;

(iii) $i$ and $j$ are directly associated through some discourse-salient group or activity.

\footnotetext{
${ }^{34}$ This can capture part-of relations between time intervals which Pearson conceives as sets of instants, in terms of subset relations holding between them.

${ }^{35}$ Note that we are treating ASK and PERMISSION here as metalanguage objects: the definitions of the ASK- and PERMISSION-alternatives should thus not be interpreted on their own as denotations for lexical items like 'ask' or 'permit'/'permission'.
} 
Where does proxy extension apply? For Pearson, the part-of semantic extension for partial control is assumed to be written into the modality of the control predicate. But as independently discussed in Sect. 6.1, proxy control sentences seem to involve a more complex modality which is reflected in a nested control structure (cf. Ex. (76)). A sentence like (80) involves two nested layers of modal quantification: concretely, the illocutionary ASK-alternatives in (81)) due to 'ask' embed the PERMISSIONalternatives in (82) due, as we have proposed, to the $C_{\text {permission }}$ that heads the control complement. This then raises the question of whether semantic proxy extension applies to the individual variable abstracted over by ASK-alternatives, as in the schema in (84)) or to the individual variable abstracted over by PERMISSION-alternatives, as in the schema in (85):

$\left[\mathrm{CP}_{1} \mathrm{Marie}_{i}\right.$ asked $\operatorname{Susan}_{j}\left[\mathrm{CP}_{2} C_{[+w h]} \mathrm{PRO}_{\text {proxy(i) }}\right.$ to (may) ${ }_{\mathrm{CP}_{3}} C_{\text {permission }}$ $\mathrm{PRO}_{\text {proxy(i) }}$ leave early]].

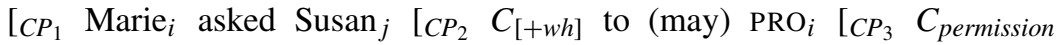
PRO $_{\text {proxy(i) }}$ leave early]].

Both the distribution of proxy control as well as the meaning of the proxy extension, defined in (83), clearly adjudicate this choice. As we have repeatedly observed, proxy control is impossible in the absence of permission modality. Concretely, this means that proxy extension cannot obtain under an object control reading of 'ask', as in (86) where such a permission modality is lacking:

$$
\begin{aligned}
& {[*] \text { Marie }_{i} \text { asked } \operatorname{Susan}_{j}\left[C_{[+w h]} \operatorname{PRO}_{\text {proxy }(j)} \text { to leave early }\right] .} \\
& \approx \text { What Marie asked Susan is that Susan's proxy leave early. }
\end{aligned}
$$

In Sect. 6.1, we argued that this restriction stems from the special nature of a proxy control predicate: while the permission that Marie asks for may be for a set of individuals that excludes Marie herself, the asking itself must be for a set of individuals that (at least) includes Marie. Taken together, this suggests that the interpretation of a proxy control sentence like (80) corresponds to the templatic structure in (85). Otherwise we would expect proxy readings to be possible in the absence of permission modality, as in (86) or, indeed, under a doxastic control predicate, as in (78).

Concretely, then, the proxy extension in a proxy OC sentence like (80), must apply only at the level of $\mathrm{CP}_{3}$, corresponding to the $\mathrm{CP}$ headed by $C_{\text {permission }}$, as templatically illustrated in (85). (80) thus states that for every triple $\left\langle x, y, w^{\prime}\right\rangle$ (where $y=$ the individual that Marie identifies as Susan in $w^{\prime}$ and $x=$ the individual that Marie identifies as herself in $w^{\prime}$ ), which is compatible with what Marie asks Susan in the actual world $w$, there is some centered world $\left\langle x^{\prime}, w^{\prime \prime}\right\rangle$ (where $x^{\prime}=$ the counterpart in $w^{\prime \prime}$ of $x$ ) which is compatible with what $x$ is permitted in $w^{\prime}$, and a corresponding individual proxy $\left(x^{\prime}\right)$ who leaves early in $w^{\prime \prime}$. This is described in (87) below: ${ }^{36}$

\footnotetext{
${ }^{36}$ As an anonymous reviewer also notes, a complete semantic analysis might ultimately need to be formulated in event semantic terms, in keeping with the event-based description of the proxy relation in Ex. (83). For the purposes of the analysis given here, events are excluded from the semantics for the sake of simplicity.
} 
a. $\left[\mathrm{CP}_{1} \lambda w\right.$ Marie asks Susan $\left[\mathrm{CP}_{2} \lambda x_{1} \lambda w_{2} \mathrm{w}_{2} \mathrm{PRO}_{1}\right.$ to be permitted $\left[\mathrm{CP}_{3}\right.$ $\lambda x_{2} \lambda w_{3} \mathrm{w}_{3} \mathrm{PRO}_{2}$ to leave early ]]]

b. $\quad \llbracket C P_{3} \rrbracket^{c, g}=\lambda x \lambda w . x$ leaves early in $w$

c. $\llbracket C P_{2} \rrbracket^{c, g}=\lambda x \lambda w^{\prime} . \exists\left\langle x^{\prime}, w^{\prime \prime}\right\rangle\left[\left\langle x^{\prime}, w^{\prime \prime}\right\rangle \in \operatorname{PERMISSION}_{x, w^{\prime}} \wedge \operatorname{proxy}\left(x^{\prime}\right)\right.$ leaves early in $w^{\prime \prime}$ ]

d. $\llbracket C P_{1} \rrbracket^{c, g}=\lambda w \cdot \forall\left\langle x, y, w^{\prime}\right\rangle\left[\left\langle x, y, w^{\prime}\right\rangle \in \mathrm{ASK}_{\text {Marie,Susan }, w} \rightarrow \exists\left\langle x^{\prime}, w^{\prime \prime}\right\rangle\right.$ $\left[\left\langle x^{\prime}, w^{\prime \prime}\right\rangle \in \operatorname{PERMISSION}_{x, w^{\prime}} \wedge \operatorname{proxy}\left(x^{\prime}\right)\right.$ leaves early in $\left.\left.\left.w^{\prime \prime}\right]\right]\right]$

\subsubsection{Deriving the one-way implication between partial and proxy OC}

We observed in Sect. 2.2.4 that there is a one-way implication in the availability of partial vs. proxy control; i.e. predicates that allow proxy control must also allow partial control, but predicates that allow partial control need not also allow proxy control. Here, we discuss how this implicational restriction may be modeled under the current analysis of proxy OC.

We have just stated that the semantic proxy extension must apply to centered worlds existentially quantified over by $C_{\text {permission }}$. But as we have just said, a proxy control reading is invariably also compatible with a partial control reading. The choice between these is determined solely on the basis of the discourse-context. The German or Italian equivalent of a sentence like (80) can readily yield a partial control reading if the discourse-scenario allows Marie to be part of the group of individuals she is asking Susan permission for. What we really need, then, is a single underspecified extension relation that applies to $C_{\text {permission }}$ which yields both proxy and partial control readings.

The proxy extension relation in (83) already gives us this desired result by virtue of subsuming the part-of semantic relation. There is, after all, no explicit restriction that states that the referent of the proxy controller cannot be included in the set of individuals denoting that controller's proxy. This means that, in a sentence like (80), the proxy extension applied to world-individual pairs existentially quantified over by $C_{\text {permission }}$ will yield not only a proxy control reading but also a partial control reading. In contrast, a predicate that allows partial control but not proxy control, like 'expect' in (78) must be derived via the more specific part-of extension in (79). Such an extension is not compatible with proxy control, since the part-of extension explicitly restricts the referent of the controllee to individuals that include the referent of the controller. This yields the desired relation that the availability of proxy control entails that of partial control, but not vice-versa. What about exhaustive oc? After all, in the cases we have seen, the availability of proxy control also entails that of exhaustive control. This choice is again determined by the discourse-context. We propose that this one-way implication can be captured in the same way. The proxy extension relation in (83) subsumes not only proxy and partial control, but also exhaustive control: after all, an individual is also, trivially speaking, her own proxy. ${ }^{37}$

\footnotetext{
${ }^{37}$ A logical alternative would be to propose that an exhaustive control reading is available when no semantic extension is applied to $C_{\text {permission }}$. But this would again imply that there are two $C_{\text {permission }}$ heads: one that allows no semantic extension to take place, and another that requires a proxy extension to apply. Barring independent evidence to the contrary, we will thus not pursue this alternative, for reasons of economy.
} 
Such a model has the non-trivial advantage of also explaining crosslinguistic variation in the availability of proxy OC. In a language like German, the control complement under a predicate like bitten ('ask') in (88) is headed by $C_{\text {permission-proxy, }}$ yielding readings which are compatible with exhaustive, partial and proxy control. But in its English counterpart in (89), which allows only exhaustive and partial OC, ask must select a control clause headed by $C_{\text {permission-partial }}$ which optionally allows a part-of extension, but crucially does not allow a proxy extension:

$$
\begin{aligned}
& \text { Maria }_{i} \text { hat } \operatorname{Susan}_{j} \text { gebeten }\left[\mathrm{PRO}_{i, i+, \text { proxy }(i)}\right. \text { früher gehen zu dürfen]. } \\
& \text { earlier go.INF to may.INF } \\
& \text { Maria has Susan asked } \text { 'Maria }_{i} \text { asked Susan } \text { [PRO }_{i, i+, \text { proxy }(i)} \text { to be allowed to leave early].' } \\
& \text { Maria }_{i} \text { asked } \operatorname{Susan}_{j}\left[\mathrm{PRO}_{i, i+, * \text { proxy(i) }}\right. \text { to be allowed to leave early]. }
\end{aligned}
$$

At the same time, Italian and German do have predicates that qualify as purely partial control predicates: e.g. hoffen ('hope') in German. Such a predicate thus still introduces a complementizer with a dedicated part-of extension semantics, yielding partial control but not proxy control. The choice of $C_{\text {permission }}$ head must thus be parametrized both across languages and across individual structures.

To summarize, there is a unique route to proxy oc (via a dedicated $C_{\text {permission-proxy }}$ head), but there are multiple routes to partial oc (either via $C_{\text {permission-proxy }}$ or via $\left.C_{\text {permission-partial }}\right)$. This gives us the desired one-way entailment relationship between partial and proxy control predicates for OC in such languages.

\subsection{Modeling proxy NOC}

We assume that cases of proxy NOC also involve nested control just as in cases of proxy OC, involving a $C_{\text {permission }}$ head in the innermost clause and an illocutionary [ $\pm \mathrm{wh}$ ] head in the medial one, given that these too involve a complex illocutionary + permission modality. The difference is that, in cases of proxy NOC, the dependency between the controller and controllee is not syntactic, but discourse pragmatic, mediated by a (silent) pronominal operator in the extended projection of the innermost controlled clause (see again Boeckx et al. 2010; Landau 2015b: and more recent work in McFadden and Sundaresan 2018). Concretely, we have proposed that proxy NOC is encoded via a syntactic $\operatorname{proxy}(i) \rightarrow \operatorname{proxy}(i)$ exhaustive control relationship holding between this perspectival pronoun in the innermost clause and the innermost controllee. As we have seen, the presence of such an operator is independently supported by the discourse-pragmatic and perspectival opacity patterns discussed in Sect. 5. This operator, denoting proxy $(i)$, discourse-pragmatically refers with the controller (which denotes $i$ ), as well as the intermediate controllee (which arguably also denotes $i$ ). This yields the superficial pattern of an $i \rightarrow \operatorname{proxy}(i)$ relation holding between the surface controller and controllee. As we have seen, it is the lack of a syntactic dependency between the innermost controllee and the controller that allows the former to bear syntactic features corresponding to $\operatorname{proxy}(i)$ (for a controller bearing features corresponding to $i$ ). The direct consequence of this is that the proxy reference of the controllee in cases of NOC is not due to semantic extension (as in cases of proxy OC), but follows directly from the interpretation of its $\operatorname{proxy}(i)$ features in syntax. The 
$C_{\text {permission }}$ head in the innermost CP thus simply introduces modal alternatives over permission worlds, with no additional semantic extension.

We are now also able to explain why a syntactic dependency between the controller and controllee is impossible in cases of proxy NOC, but necessitated in cases of proxy OC. For proxy OC, we have argued that $C_{\text {permission }}$ is the phasal head of the control complement and can thus serve as an escape hatch for syntactic dependencies out of the CP. The impossibility of such a syntactic dependency in cases of proxy NOC shows that the Agree operation already successfully terminates within the phase represented by the innermost controlled clause. Independent evidence from Sect. 5 has shown that, in cases of proxy NOC, this controlled clause does contain additional structure which hosts a logophoric/perspectival operator. This pronominal operator constitutes an appropriate goal for the probing controllee, and since it is minimally closer to the probe, any element (including the controller) in the matrix clause is automatically ruled out as a potential goal. We assume that the Agree operation between the controllee and the logophoric operator must proceed via $C_{\text {permission }}$ (in parallel with cases of proxy OC), explaining why any proxy control in the absence of this head is impossible. ${ }^{38}$ The life-cycle of a proxy NOC sentence is thus as in (90) below. Note that we are not showing the dependencies between the innermost $\mathrm{CP}$ and the medial one for purposes of simplicity, since this doesn't play a crucial role in the proxy NOC relationship:

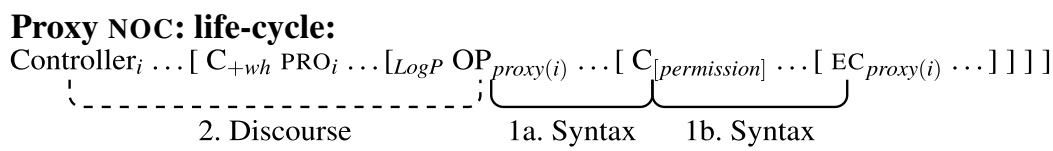

\section{Modeling inter- and intra-speaker variation for proxy control}

We now turn to the question of how variation for proxy control is encoded. We are particularly interested in the following questions. In proxy control languages like Italian and German, what is the locus of dialectal variation for proxy OC vs. proxy NOC? What factors condition the choice between exhaustive vs. partial vs. proxy control, under a given control predicate?

Consider again our tableau of speaker-types from our tested pool of consultants in German and Italian:

\section{Schema of speaker types}

\begin{tabular}{l|l|l}
\hline & $\checkmark$ PROXY & $\boldsymbol{X}$ PROXY \\
\hline OC & PROXY OC SPEAKERS & NON-PROXY OC SPEAKERS \\
NOC & PROXY NOC SPEAKERS & NON-PROXY NOC SPEAKERS \\
\hline
\end{tabular}

\footnotetext{
${ }^{38}$ We remain agnostic for now about whether the perspectival head associated with the perspectival pronoun constitutes the phasal head of the controlled clause or whether the phasal head is still higher than this. Since the Agree operation successfully terminates at this stage, within the CP phase of the controlled clause, the Agree operation will simply not proceed further outside this phase.
} 
a. PROXY OC SPEAKERS accept proxy readings with proxy control predicates and pass OC diagnostics (i.e. fail NOC diagnostics);

b. NON-PROXY OC SPEAKERS allow varieties of OC under proxy control predicates, but crucially do not allow proxy oC itself;

c. PROXY NOC SPEAKERS allow proxy control readings but only as a variety of NOC;

d. NON-PROXY NOC SPEAKERS disallow not only proxy OC but also exhaustive and partial OC under proxy control predicates.

\subsection{Modeling inter-speaker variation for PROXY OC vS. PROXY NOC}

OUR PROXY OC SPEAKERS and PROXY NOC SPEAKERS both allow proxy control readings and differ only with respect to whether such a control relation bears the hallmarks of OC or NOC, respectively. Given the discussion above, this difference must stem from selectional variation for a given control predicate. For PROXY OC speakers, the innermost control CP phase under a predicate like 'ask' must be headed by $C_{\text {permission }}$ and (arguably as a result) lack higher structural material that could provide a closer goal for the probing controllee. Similarly, the medial CP headed by the illocutionary $\mathrm{C}$ head must also head this $\mathrm{CP}$, such that it can mediate further Agree operations between the medial controllee and the matrix controller (cf. 76). Thus, proxy OC obtains via mediated Agree relations holding between the controller and two nested controllees. For PROXY NOC speakers, the innermost controlled CP hosting $C_{\text {permission }}$, under 'ask', must bear additional structure (making it "more finite") which hosts a perspectival operator that serves as a closer goal for the probing (innermost) controllee. The perspectival operator bears features corresponding to $\operatorname{proxy}(i)$ and thus values the features of the innermost controllee also as proxy $(i)$. The operator discourse-pragmatically refers to the controller (denoting $i$ ) yielding a superficial $i \rightarrow \operatorname{proxy}(i)$ NOC relation. Thus, for both categories of speaker, the $C_{\text {permission }}$ head must be part of the extended projection of the innermost controlled clause: it heads this CP for PROXY OC speakers but not for PROXY NOC speakers. For PROXY OC speakers, $C_{\text {permission }}$ must additionally be lexically specified to allow proxy semantic extension; for PROXY NOC proxy control does not involve semantic extension.

If we are correct in this line of thinking, we make the following empirical predictions: PREDICTION I: PROXY OC SPEAKERS must also allow partial and exhaustive OC under the same predicates. PREDICTION II: PROXY NOC SPEAKERS must also accept partial and exhaustive NOC under the same predicates. PREDICTION III: PROXY NOC SPEAKERS must require OC under non-proxy control predicates like 'try'.

Turning to PREDICTION I, the proxy semantic extension (over the individual variable quantified over by $C_{\text {permission-proxy }}$ ) subsumes both the part-of extension of partial control as well as the identity extension of exhaustive control (cf. Sect. 7.1.3): i.e. a part-of relation is a particular kind of proxy relation; similarly, an individual may, in theory, serve as her own proxy. The choice between proxy vs. partial vs. exhaustive OC stems solely from discourse pragmatic factors. Thus, we predict that partial OC and exhaustive OC should be possible wherever proxy OC is. This expectation is fulfilled. There were no speakers in our survey who allowed proxy oc under some predicate but disallowed exhaustive or partial oc under the same predicate. 
Turning to PREDICTION II, the choice between exhaustive vs. partial vs. proxy NOC, for our PROXY NOC SPEAKERS, simply has to do with the (referential) features of the logophoric pronoun that Agrees with the $C_{\text {permission }}$ head and the controllee. If this pronoun happens to be coreferent with the controller, we predict exhaustive NOC; if it denotes $i+$ for a controller $i$, we predict partial NOC; if it denotes $\operatorname{proxy}(i)$ for a controller $i$, we predict proxy NOC. Assuming that the choice of referent for this pronoun is free, and plausibly only constrained by properties of the discoursecontext or factors pertaining to sentence-processing, PROXY NOC SPEAKERS should also accept partial and exhaustive NOC readings for such predicates. This prediction is also fulfilled. In contrast to PROXY OC SPEAKERS, PROXY NOC SPEAKERS also readily accept strict readings under ellipsis for exhaustive and partial control readings of ask-sentences. Similarly, they readily accept non-local antecedents for exhaustive, partial and proxy readings alike for these predicates.

Finally, we predict that PROXY NOC SPEAKERS must require OC for controlled clauses that do not constitute a strong phase, and thus allow a syntactic dependency (mediated or direct) between the controller and controllee. Control complements of predicates like 'try' have been shown to fall into this category: such clauses have been independently noted to allow more transparency between the matrix and embedded clauses with respect to various finiteness metrics such as sequence-of-tense and -mood, and exhaustive reference (see Wurmbrand 2001; Landau 2004; Grano 2012; Wurmbrand 2014b, and references therein). This prediction (prediction III) is also met: our PROXY NOC SPEAKERS do not universally disallow OC under all control predicates, only under varieties of control predicate (including proxy control predicates) whose control complements are more independent with respect to tense, mood, and reference. We take the confirmation of these empirical predictions as strong evidence in support of the model of variation proposed here.

\subsection{Modeling intra-speaker variation for PROXY OC vs. PROXY NOC}

What about those speakers that allow both proxy OC and NOC under proxy control predicates? A good portion of our consultants, corresponding to all groups (except that of NON-PROXY OC SPEAKERS), accepted sentences that violated Condition B, as in (92b) (cf. (50b)): : $^{39}$

a. Scenario: Antje, Diana and Malte want to run their experiment in the chemistry lab. In general, the chemistry lab may only be used by students when a teacher is present. The class teacher, Herr Schmidt, cannot be present himself this time and so he asks the person in charge of the lab that the three students may use the lab without him. The person in charge of the lab consents and so the three students run their experiment in the lab.

\footnotetext{
${ }^{39}$ As an anonymous reviewer notes, this is tantamount to claiming that the co-reference between the matrix controller and the pronoun in the control complement is enforced. We attempted to address this issue by keeping the gender between the controller and the indirect object separate, and making sure that the context is clear and does not invite any generic third party into the discourse.
} 
b. Herr Schmidt ${ }_{i}$ hat die Verantwortliche ${ }_{j}$ gebeten, [EC $_{\text {proxy(i) }}$ das

$\mathrm{Mr}$ Schmidt has the responsible.F asked the

Experiment dieses Mal ohne $\mathrm{ihn}_{i}$ im Labor durchführen $\mathrm{zu}$ experiment this time without him in.the lab run.INF to dürfen.]. may.INF

'Mr. Schmidt asked the person in charge of the lab (for permission for the three students) to run the experiment in the lab without him this time.'

This tendency is also reflected in the mean ratings of the three groups for this sentence type. Collapsing the two surveys, PROXY OC SPEAKERS gave a mean rating of 3.75, NON-PROXY OC SPEAKERS 2.00, PROXY NOC SPEAKERS 3.08, and NON-PROXY NOC SPEAKERS of 3.38. The acceptance of (92b) (or (50b)) was puzzling until we realized that such speakers also allowed strict readings under ellipsis with this sentence. Crucially, this was the case even if such speakers disallowed strict readings under ellipsis elsewhere (in other words, seemed to belong to the group of PROXY OC speakers). We thus concluded that an NOC structure must be selected by the matrix predicate in such cases (recall the discussion in Sect. 4.2.2) even for PROXY OC speakers.

First, what is the source of the proxy OC vs. NOC ambiguity for a speaker in the PROXY OC category? Given our discussion of the choice between proxy OC vs. NOC in Sect. 8.1 above, the answer to this can only be that, for such speakers, a proxy control predicate like 'ask' can optionally select control complements with different structural properties. When the innermost CP under 'ask' is headed by $C_{\text {permission, }}$, the result is a configuration that is transparent to mediated Agree between the controller and controllee, as illustrated in (76). When the innermost CP is syntactically opaque due to additional logophoric material in the clausal periphery, yielding a $\mathrm{CP}$ that contains $C_{\text {permission }}$ in its phasal domain, the Agree relation between the controller and $C_{\text {permission }}$ is blocked and proxy NOC is enforced.

Second, what forces an NOC parse in cases like (92) for PROXY OC speakers who do not allow NOC in the minimal variant of this sentence without the pronoun ${ }^{40} \mathrm{We}$ speculate that, at least for our PROXY OC speakers, the selection of a reduced control complement under a predicate like 'ask', yielding proxy OC, is strongly preferred. Such speakers require overt syntactic evidence to exclude this preferred oc parse in favor of an NOC parse. Such overt evidence could come in the form of a coreferent pronoun as in German (92b), or a FQ with agreement that doesn't match the features of the controller (as in Italian). It further seems plausible to us that speakers might vary with respect to how much evidence they need to choose an NOC parse of permission-seeking or -granting control sentences over an OC interpretation.

\footnotetext{
${ }^{40}$ Note that, while it is tempting to conclude from this that all proxy oc is simply a pragmatically restricted variant of proxy NOC, we have shown conclusively in Sect. 4 that this is, in fact, not the case. Proxy OC and proxy NOC are, ultimately, genuinely distinct forms of control.
} 


\subsection{Modeling variation for NON-PROXY OC vS. NON-PROXY NOC}

We have just argued that the choice between proxy OC vs. NOC has to do with whether the controlled complement of the proxy verb is transparent for Agree or not. Such clausal transparency is a necessary condition for proxy OC to obtain, just as clausal opacity is a necessary condition for proxy NOC to obtain. But it is ultimately not a sufficient condition.

OUR NON-PROXY OC SPEAKERS allow exhaustive and partial OC under a predicate like 'ask' but disallow proxy OC. The fact that such speakers parse control under 'ask' as OC must mean that the innermost control complement is transparent to Agree: i.e. is headed by $C_{\text {permission. }}$. Why do such speakers disallow proxy OC in this scenario? For us this follows directly from the idea that, for such speakers, the $C_{\text {permission }}$ head in the control complement is not lexically specified to allow a proxy semantic extension. Rather, $C_{\text {permission }}$ is lexically specified to optionally allow the more restricted part-of semantic extension described in (79). This class of NON-PROXY OC SPEAKERS in German and Italian thus has an English-like grammar: exhaustive and partial OC are licit under a predicate like 'ask', but proxy OC is not.

The category of NON-PROXY NOC SPEAKERS involves speakers that allow only exhaustive and partial NOC under permission-seeking and -granting predicates. As NOC speakers, the innermost control CP of 'ask' must instantiate an opaque phasal domain, precluding a syntactic dependency between the controller and controllee. We thus predict that NON-PROXY NOC SPEAKERS should disallow not only proxy OC but also partial and exhaustive OC under a proxy control predicate. This prediction is also met, suggesting again that, while structural differences regulate the choice between OC and NOC, they do not influence the degree of exhaustivity in the control relation. Interestingly, NON-PROXY NOC SPEAKERS allow exhaustive and partial NOC under a proxy control predicate. It is less clear why proxy NOC should be impossible in this case since, as we have discussed above, the choice between these readings reduces to the possible reference of the logophoric operator in the control clause. We propose here that the answer may simply be a functional one, having to do with processing difficulty. For such speakers, an $i \rightarrow \operatorname{proxy}(i)$ discourse pragmatic relation (between the logophoric operator and the controller) is more difficult to process than an $i \rightarrow i$ or $i \rightarrow i+$ relation. Potential evidence for this comes from the fact that there were no speakers among our consultants that disallowed the simpler versions of NOC, e.g. exhaustive and partial NOC, while allowing proxy NOC.

\section{Conclusion}

The goal of this paper has been to show that, in addition to the exhaustive $i \rightarrow i$ and the classic non-exhaustive relation of the form $i \rightarrow i+$, control dependencies in certain languages may also be interpreted in terms of an $i \rightarrow \operatorname{proxy}(i)$ relation, defined as in (93):

\section{Generalized proxy control (OC and NOC) relation:}

a. For any two sets of individuals $i$ and $j$, where $i$ is a core participant in a permission-seeking or -granting speech-event $e_{1}$ and $j$ is a core participant in $e_{2}$, an eventuality that is consistent with permission being granted in $e_{1}, j=\operatorname{proxy}(i)$ iff: 
(i) in $e_{1}, i$ acts on behalf of $j$;

(ii) in $e_{2}, j$ stands in for $i$;

(iii) $i$ and $j$ are directly associated through some discourse-salient group or activity.

b. In cases of proxy control, if a controller denotes $i$ and the controllee denotes $j, j=\operatorname{proxy}(i)$.

We have presented evidence, based on primary data gathered from varieties of German and Italian, to argue that proxy control is available both as a species of NOC and $\mathrm{OC}$, and, furthermore, that it constitutes a genuinely new form of control relation in grammar, irreducible to other more familiar referential dependencies. We have also shown in detail that proxy OC is not reducible to proxy NOC. To this end, we have presented evidence involving pragmatic insensitivity and perspectival opacity to argue that the innermost control complement in proxy NOC constructions involves additional logophoric structure that is absent in corresponding sentences involving proxy OC.

Both proxy OC and proxy NOC involve nested (or cyclic) control. In cases of proxy OC, the Agree relationship between the controller and intermediate and innermost controllees is syntactic because it is mediated by the phase heads, an illocutionary $\mathrm{C}$ head in the medial clause and $C_{\text {permission }}$ in the innermost one, of the respective clauses. The syntactic nature of this dependency prevents the controllees from bearing syntactic features corresponding to $\operatorname{proxy}(i)$ : this is reflected by the fact that the controllee cannot feed agreement on an associated floating quantifier in Italian or obviate Condition B effects in German. We have thus proposed that the proxy OC dependency is syntactically encoded as an $i \rightarrow i$ relation. The individual $i$ coordinate of the innermost controllee (corresponding to the individual variable abstracted over by the $C_{\text {permission }}$ modal) is then semantically extended to yield proxy $(i)$, building on insights in Pearson (2016) for cases of partial control. The one-way entailment between proxy vs. partial control is captured under the idea that the part-of extension in cases of partial control represents a special kind of proxy relation. But the reverse is not the case: a proxy relation need not be a part-of relation.

For cases of proxy NOC, our floating quantifier facts in Italian and Condition B obviation facts in German show that the $\operatorname{proxy}(i)$ reference of the (innermost) controllee is, in fact, syntactically established. However, given that this is NOC, there is no syntactic relation between the controller and this controllee in such cases. We have proposed, following McFadden and Sundaresan (2018) and others that this controllee is bound by a silent logophoric pronoun in its clausal periphery and provided independent evidence in Sect. 5 for the presence of such a pronoun. The logophoric operator denotes $\operatorname{proxy}(i)$, yielding in effect a $\operatorname{proxy}(i) \rightarrow \operatorname{proxy}(i)$ relation in the syntax. The operator $\operatorname{proxy}(i)$ in turn discourse-semantically refers with the controller $i$ in the discourse-semantics, yielding a superficial $i \rightarrow \operatorname{proxy}(i)$ NOC pattern.

Finally, we have discussed two types of intra- and inter-speaker variation for proxy control: (i) the variation between exhaustive, partial and proxy control (both OC and NOC) under a permission-seeking or -granting predicate, and (ii) the variation be- 
tween proxy OC vs. proxy NOC, in a grammar (language or dialect) that already allows proxy control. We have shown that in cases of OC, (i) depends on the availability and semantic properties of the modal $C_{\text {permission }}$ complementizer in the control complement of a permission-seeking or -granting predicate, specifically on whether this head is compatible with a proxy extension or only with an optional part-of extension. Degrees of exhaustivity for NOC obtain directly as a function of the reference $(i, i+$ or $\operatorname{proxy}(i))$ of the logophoric operator in the innermost CP. (ii) depends on the structural properties of the $C_{\text {permission }}$ complementizer in the innermost controlled clause, which Agrees with the controllee both in cases of OC and NOC-concretely, whether this head is syntactically accessible to a controller in an immediately higher clause, or not. We have shown that this model makes correct empirical predictions for the grammar of our consultants across categories.

We have restricted ourselves in this paper to primary data from varieties of German and Italian where we have the most robust data. But initial investigations of Hindi, English (e.g.: ?Maria ${ }_{i}$ asked Susan $_{j}$ [about $\mathrm{PRO}_{\text {proxy(i) }}$ leaving early]), and Hebrew, based on consultations with native speakers, suggest that proxy control is also available in these languages. In Hindi and English, this seems to be possible only as a case of NOC, but in Hebrew, speakers vary with respect to whether this is instantiated as OC or NOC (see also recent work in Naaman 2019). A more preliminary survey of languages including Indonesian, Romanian, French, Tsez, and Japanese shows that proxy control is also attested here, though further testing is needed to determine its OC vs. NOC status. This paper serves as an initial contribution on proxy control with the larger goal of showing that the typology of possible control relations in language is broader and more nuanced than has been previously assumed. The research agenda for future work on this phenomenon must involve careful empirical work on primary data to determine the distribution of proxy control across languages and the factors that condition its variation.

Acknowledgements We thank the following individuals for their generous feedback on different versions of this paper: Rajesh Bhatt, Valentine Hacquard, Norbert Hornstein, Idan Landau, Howard Lasnik, Robert Pasternak, Paul Pietroski, Marcel Pitteroff, Barbara Stiebels and, most especially, Thomas McFadden. We are also indebted to our native speaker consultants, too many to individually name here, without whose patient and careful judgments this paper simply wouldn't have been possible. Many thanks, also, to the audiences at: S-Lab (U. of Maryland), GLOW-in-Asia XI (Singapore), CGSW 31 (Stellenbosch), IATL 32 (Jerusalem), Workshop on Pronouns: Morphosyntax, Semantics, Processing (Salvador), and at invited talks in colloquia at the University of Köln \& ZAS Berlin and at the workshop on Non-Finite Subjects (Nantes) - for their constructive feedback on earlier versions of this paper. Finally, we would also like to acknowledge four anonymous reviewers for their extremely meticulous and useful critique of this paper, which significantly helped to improve it in content and presentation. All errors are our own.

Funding Note Open Access funding enabled and organized by Projekt DEAL.

Publisher's Note Springer Nature remains neutral with regard to jurisdictional claims in published maps and institutional affiliations.

Open Access This article is licensed under a Creative Commons Attribution 4.0 International License, which permits use, sharing, adaptation, distribution and reproduction in any medium or format, as long as you give appropriate credit to the original author(s) and the source, provide a link to the Creative Commons licence, and indicate if changes were made. The images or other third party material in this article are included in the article's Creative Commons licence, unless indicated otherwise in a credit line to the material. 
If material is not included in the article's Creative Commons licence and your intended use is not permitted by statutory regulation or exceeds the permitted use, you will need to obtain permission directly from the copyright holder. To view a copy of this licence, visit http://creativecommons.org/licenses/by/4.0/.

\section{References}

Abusch, Dorit. 1997. Sequence of tense and temporal de re. Linguistics and Philosophy 20(1): 1-50. https://doi.org/10.1023/A:1005331423820.

Anand, Pranav, and Valentine Hacquard. 2013. Epistemics and attitudes. Semantics and Pragmatics 6: $1-59$.

Bhatt, Rajesh. 2006. Covert modality in non-finite context. Vol. 8 of Interface explorations. The Hague: Mouton de Gruyter.

Bhatt, Rajesh, and Roumyana Izvorski. 1998. Genericity, implicit arguments and control. In Student Conference in Linguistics (SCIL) 7.

Bjorkman, Bronwyn, and Hedde Zeijlstra. 2019. Checking up on “(phi-) agree”. Linguistic Inquiry 50(3) 527-569.

Boeckx, Cedric, Norbert Hornstein, and Jairo Nunes. 2010. Control as movement. Vol. 126 of Cambridge studies in linguistics. Cambridge: Cambridge University Press.

Chierchia, Gennaro. 1989. Structured meanings, thematic roles, and control. In Properties, types, and meaning, eds. Gennaro Chierchia, Barbara Partee, and Raymond Turner. Vol. 2: Semantic Issues of Studies in linguistics and philosophy, 131-166. Dordrecht: Kluwer Academic.

Chomsky, Noam. 1973. Conditions on transformations. In A festschrift for Morris Halle, eds. Stephen Anderson and Paul Kiparsky, 232-286. New York: Academic Press.

Chomsky, Noam. 2000. Minimalist inquiries: The framework. In Step by step: Essays on minimalist syntax in honour of Howard Lasnik, eds. Roger Martin, David Michaels, and Juan Uriagereka, 89-155. Cambridge: MIT Press.

Chomsky, Noam. 2001. Derivation by phase. In Ken Hale: A life in language, ed. Michael Kenstowicz, 1-52. Cambridge: MIT Press.

Cinque, Guglielmo. 1999. Adverbs and functional heads: A cross-linguistic perspective. New York: Oxford University Press.

Farkas, Donka F. 1988. On obligatory control. Linguistics and Philosophy 11(1): 27-58.

Fischer, Silke. 2018. Locality, control, and non-adjoined islands. Glossa, A Journal of General Linguistics 82(3(1)): 1-40. https://doi.org/10.5334/gjgl.182.

Frascarelli, Mara. 2007. Subjects, topics and the interpretation of referential pro. Natural Language and Linguistic Theory 25: 691-734.

Grano, Thomas. 2012. Control and restructuring at the syntax-semantics interface. PhD diss., University of Chicago.

Hacquard, Valentine. 2006. Aspects of modality. PhD diss., MIT.

Hornstein, Norbert. 1999. Movement and control. Linguistic Inquiry 30: 69-96.

Hornstein, Norbert. 2003. On control. In Minimalist syntax, ed. Randall Hendrick, 6-81. Oxford: Blackwell.

Iatridou, Sabine. 1990. About Agr(P). Linguistic Inquiry 21(4): 551-576. http://www.jstor.org/stable/ 4178695 .

Jackendoff, Ray. 1992. Mme. Tussaud meets the binding theory. Natural Language and Linguistic Theory 10: 1-31.

Kuno, Susumu. 1975. Super Equi-NP deletion is a pseudo-transformation. In North East Linguistic Society (NELS) 5, 29-44.

Landau, Idan. 2004. The scale of finiteness and the calculus of control. Natural Language and Linguistic Theory 22: 811-877.

Landau, Idan. 2008. Two routes of control: Evidence from case transmission in Russian. Natural Language and Linguistic Theory 26: 877-924.

Landau, Idan. 2013. Control in generative grammar. Cambridge: Cambridge University Press.

Landau, Idan. 2015a. Direct variable binding and agreement in obligatory control. Ms., Ben Gurion University.

Landau, Idan. 2015b. A two-tiered theory of control. Cambridge: MIT Press.

Landau, Idan. 2016. Against the null comitative analysis of partial control. Linguistic Inquiry 47(3): 572580 . 
Lasersohn, Peter. 2005. Context dependence, disagreement, and predicates of personal taste. Linguistics and Philosophy 28: 643-686.

Lasnik, Howard, and Robert Fiengo. 1974. Complement object deletion. Linguistic Inquiry 5(4): 535-571.

Lewis, D. 1979. Attitudes de dicto and de se. Philosophical Review 88: 513-543.

McFadden, Thomas, and Sandhya Sundaresan. 2016. Failure to control is not a failure: It's pro. In North East Linguistic Society (NELS) 46, eds. Christopher Hammerly and Brandon Prickett, Vol. 3, 1-10. Amherst: GLSA.

McFadden, Thomas, and Sandhya Sundaresan. 2018. Reducing pro and PRO to a single source. The Linguistic Review 35(3): 463-518.

Naaman, Limor. 2019. Proxy control in Hebrew. Master's thesis, University of Leipzig.

Nunberg, Geoffrey. 1979. The non-uniqueness of semantic solutions: polysemy. Linguistics and Philosophy 3: 143-184.

Pearson, Hazel. 2016. The semantics of partial control. Natural Language and Linguistic Theory 34: 691738.

Petter, Marga. 1998. Getting PRO under control. Vol. 8 of LOT international series. The Hague: HIL, Holland Academic Graphics.

Pitteroff, Marcel, and Michelle Sheehan. 2018. The case for fake partial control in French and German. In North East Linguistic Society (NELS) 48, eds. Sherry Hucklebridge and Max Nelson, Vol. 2, 245258. Amherst: GLSA.

Pitteroff, Marcel, Artemis Alexiadou, and Silke Fischer. 2017a. Two mechanisms to derive partial control: Evidence from German. In University of Pennsylvania working papers in linguistics, Vol. 23, 201210. Philadelphia.

Pitteroff, Marcel, Artemis Alexiadou, Jeannique Darby, and Silke Fischer. 2017b. On partial control in German. Journal of Comparative Germanic Linguistics 20: 139-185.

Postal, Paul. 2004. Skeptical linguistic essays. New York: Oxford University Press.

Reinhart, Tanya. 1983. Anaphora and semantic interpretation. Croom helm linguistics series: Anaphora. Croom Helm.

Reuland, Eric, and Yoad Winter. 2009. Binding without identity: Towards a unified semantics for bound and exempt anaphors. In 7th discourse anaphora and anaphor resolution colloquium.

Rizzi, Luigi. 1986. Null objects in Italian and the theory of pro. Linguistic Inquiry 17(3): 501-557.

Rodrigues, Cilene. 2007. Agreement and flotation in partial and inverse partial control configurations. In New horizons in the analysis of control and raising, eds. William D. Davies and Stanley Dubinsky, 213-229. Dordrecht: Springer.

Ross, John Robert. 1967. Constraints on variables in syntax. PhD diss., MIT, Cambridge.

Sag, Ivan, and Carl Pollard. 1991. An integrated theory of complement control. Language 67: 63-113.

Schladt, Mathias. 2000. The typology and grammaticalization of reflexives. In Reflexives: Forms and functions, eds. Zygmunt Frajzyngier and Traci Curl. Amsterdam: Benjamins.

Sheehan, Michelle. 2012. A new take on partial control: An overview. Cambridge Occasional Papers in Linguistics 6: 1-47.

Sheehan, Michelle. 2014. Partial control in the Romance languages: The covert comitative analysis. In Romance languages and linguistic theory 2012: Papers from 'Going Romance', Leuven 2012, eds. Karen Lahousse and Stefania Marzo, 181-198. Amsterdam: Benjamins.

Słodowicz, Szymon. 2008. Control in Polish complement clauses. Munich: Otto Sagner.

Stephenson, Tamina. 2007. Judge dependence, epistemic modals, and predicates of personal taste. Linguistics and Philosophy 30: 487-525.

Stiebels, Barbara. 2007. Towards a typology of complement control. ZAS Papers in Linguistics 47: 1-80.

Sundaresan, Sandhya. 2012. Context and (co)reference in the syntax and its interfaces. PhD diss., University of Troms $\varnothing /$ Universität Stuttgart, Tromsø.

Sundaresan, Sandhya. 2018. Perspective is syntactic: Evidence from anaphora. Glossa: A Journal of General Linguistics 128(3(1)). https://doi.org/10.5334/gjgl.81.

Uegaki, Wataru. 2011. Controller shift in centered-world semantics. Presented at The Grammar of Attitudes: DGfS Workshop, University of Göttingen.

White, Aaron Steven, and Thomas Grano. 2014. An experimental investigation of partial control. In Proceedings of Sinn und Bedeutung, eds. Urtzi Exteberria, Anamaria Fălăuş, Aritz Irurtzun, and Bryan Leferman, Vol. 18, 469-486.

Williams, Edwin. 1980. Predication. Linguistic Inquiry 11: 203-238.

Wurmbrand, Susi. 2001. Infinitives: Restructuring and clause structure. Berlin: Mouton de Gruyter. 
Wurmbrand, Susi. 2002. Syntactic vs. semantic control. In Studies in comparative Germanic syntax, eds. C. Jan-Wouter Zwart and Werner Abraham, 95-129. Amsterdam: Benjamins.

Wurmbrand, Susi. 2014a. The Merge condition: a syntactic approach to selection. In Minimalism and beyond: Radicalizing the interfaces, eds. Peter Kosta, Steven L. Franks, Teodora Radeva-Bork, and Lilia Schürcks, 130-166. Philadelphia: Benjamins.

Wurmbrand, Susi. 2014b. Tense and aspect in English infinitives. Linguistic Inquiry 45: 403-447. 